\title{
Understanding the SAM influence on the South Pacific ENSO teleconnection
}

\author{
Ryan L. Fogt • David H. Bromwich • \\ Keith M. Hines
}

Received: 11 September 2009/Accepted: 3 September 2010

(C) Springer-Verlag 2010

\begin{abstract}
The relationship between the El Niño Southern Oscillation (ENSO) and the Southern Hemisphere Annular Mode (SAM) is examined, with the goal of understanding how various strong SAM events modulate the ENSO teleconnection to the South Pacific $\left(45^{\circ}-70^{\circ} \mathrm{S}, 150^{\circ}-\right.$ $\left.70^{\circ} \mathrm{W}\right)$. The focus is on multi-month, multi-event variations during the last 50 years. A significant $(p<0.10)$ relationship is observed, most marked during the austral summer and in the 1970s and 1990s. In most cases, the significant relationship is brought about by La Niña (El Niño) events occurring with positive (negative) phases of the SAM more often than expected by chance. The South Pacific teleconnection magnitude is found to be strongly dependent on the SAM phase. Only when ENSO events occur with a weak SAM or when a La Niña (El Niño) occurs with a positive (negative) SAM phase are significant South Pacific teleconnections found. This modulation in the South Pacific ENSO teleconnection is directly tied to the interaction of the anomalous ENSO and SAM transient eddy momentum fluxes. During La Niña/SAM+ and El Niño/ SAM - combinations, the anomalous transient momentum fluxes in the Pacific act to reinforce the circulation
\end{abstract}

Contribution 1400 of the Byrd Polar Research Center.

R. L. Fogt $(\bowtie)$

Department of Geography, Ohio University,

122 Clippinger Laboratories, Athens, OH 45701, USA

e-mail: fogtr@ohio.edu

D. H. Bromwich - K. M. Hines

Polar Meteorology Group, Byrd Polar Research Center,

The Ohio State University, Columbus, OH, USA

D. H. Bromwich

Atmospheric Sciences Program, Department of Geography,

The Ohio State University, Columbus, OH, USA anomalies in the midlatitudes, altering the circulation in such a way to maintain the ENSO teleconnections. In La Niña/SAM - and El Niño/SAM+ cases, the anomalous transient eddies oppose each other in the midlatitudes, overall acting to reduce the magnitude of the high latitude ENSO teleconnection.

\section{Introduction}

Compared to the Northern Hemisphere, regional climate variations in the Southern Hemisphere are much less understood. This in part stems from shorter and comparatively less dense observational records in the Southern Hemisphere. Yet, significant regional climate changes in the high latitudes of the Southern Hemisphere have been detected. Recently, Steig et al. (2009) demonstrated that significant warming since the International Geophysical Year (IGY) - previously thought confined to the Antarctic Peninsula-is much broader in spatial extent, with significant warming also extending to West Antarctica. The regional asymmetry in warming across the Antarctic continent is also reflected in sea ice changes. During the last decade, sea ice concentrations/extents have been anomalously low in the Amundsen/Bellingshausen Seas sector (Yuan and Martinson 2000; Zwally et al. 2002; Stammerjohn et al. 2008). The reduced sea ice in this region contrasts with anomalously positive sea ice extent anomalies in the adjacent Ross Sea sector (Comiso and Nishio 2008; Lefebvre et al. 2004).

A possible mechanism for these regional climate changes stems from the South Pacific atmospheric circulation, a region influenced by both the Southern Hemisphere Annular Mode (SAM) and the El Niño-Southern Oscillation (ENSO). The SAM describes the strength of the mid- 
to-high latitude meridional pressure gradient and circumpolar zonal winds. Although ENSO is a tropical climate oscillation, it impacts the whole globe through atmospheric teleconnections. In the high southern latitudes, an ENSO teleconnection is found in the South Pacific $\left(45^{\circ}-70^{\circ} \mathrm{S}\right.$, $150^{\circ}-70^{\circ} \mathrm{W}$ ) off the West Antarctic coast. This center is part of an alternating wave-train of pressure/height anomalies originating from the Tropics during ENSO events known as the Pacific South American pattern (Mo and Ghil 1987; Karoly 1989; Renwick and Revell 1999; Mo and Paegle, 2001; Bromwich et al. 2004; Turner 2004; Yuan 2004; Lachlan-Cope and Connolley 2006).

Over the last decade, the combined impact of SAM and ENSO events on the South Pacific atmospheric circulation has garnered increasingly more attention (Kwok and Comiso 2002; Fogt and Bromwich 2006; L'Heureux and Thompson 2006; Gregory and Noone 2008; Stammerjohn et al. 2008). In particular, Fogt and Bromwich (2006) found that the decadal variability of the ENSO teleconnection to the South Pacific is related to the coupling with the SAM. SAM and ENSO combinations also impact the timing of the regional sea ice retreat and advance (Stammerjohn et al. 2008). However, Sterl et al. (2007) use observational and modeling data to argue that temporal changes in global ENSO teleconnections are random and not governed by physical mechanisms such as the SAM. They further suggest that the Fogt and Bromwich (2006) study is too short to determine significant changes in teleconnection strength. If in fact the variations of ENSO teleconnection strength arise by chance, then their future magnitude is virtually unpredictable, despite their known impacts in West Antarctica (Bromwich et al. 2004; Schneider and Steig 2008).

There are three main objectives to this paper. First, we investigate the ENSO-SAM relationship further in order to highlight its marked seasonal and decadal variability. Second, we demonstrate that the SAM phase and magnitude plays a significant role on the South Pacific ENSO teleconnection. Lastly, we demonstrate that the South Pacific ENSO teleconnection variations result from interactions of ENSO-induced and SAM-induced anomalous transient eddy momentum fluxes, which are most marked in the Pacific sector. In order to remove unrelated highfrequency climate noise and subtle inter-event variations, the focus of the current analysis is on the mean teleconnection magnitude and location over the course of many ENSO events during the last 50 years. In so doing, the analysis of Fogt and Bromwich (2006) is extended to more than five decades and to all seasons. Our focus is on the troposphere, since ENSO originates in the troposphere and its poleward propagation via the Pacific South American pattern is predominantly tropospheric (Mo and Ghil 1987; Karoly 1989; Renwick and Revell 1999).

\section{Data and methods}

All analysis is conducted for January 1957 to February 2009. To be consistent with previous studies (i.e., L'Heureux and Thompson 2006; Carvalho et al. 2005), ENSO activity is defined using sea surface temperature (SST) anomalies. In this study, the Niño 3.4 region $\left(5^{\circ} \mathrm{N}-5^{\circ} \mathrm{S}\right.$, $170^{\circ} \mathrm{W}-120^{\circ} \mathrm{W}$ ) Extended Reconstruction SST Version 3B (ERSST.V3B; Smith et al. 2008) anomalies, available from the Climate Prediction Center (CPC; http://www.cpc. noaa.gov/), are used. For the SAM, the observation-based definition of Marshall (2003) is used. To examine the spatial atmospheric circulation anomalies and the corresponding South Pacific ENSO teleconnection variations, the Hadley Centre gridded mean sea level pressure (MSLP) data (HadSLP2; Allan and Ansell 2006) and various fields from the National Centers for Environmental Prediction/ National Center for Atmospheric Research reanalysis (hereafter, NCEP; Kalnay et al. 1996) are used. Although the pre-satellite (i.e., before 1979) reanalysis data are suspect in the high southern latitudes (Hines et al. 2000; Bromwich and Fogt 2004; Bromwich et al. 2007), we will demonstrate that nearly identical results are obtained using only the potentially more reliable post 1978 data. Further, the HadSLP2 data have smaller biases and higher correlations with station observations than the NCEP pressure data prior to 1979 (Jones and Lister 2007), therefore justifying their use and increasing the confidence in our results.

To investigate changes in the ENSO teleconnection related to the SAM, Fogt and Bromwich (2006) used both correlation and composite analysis. However, correlation analysis may not always provide the best insight on the ENSO teleconnection variations, for at least two reasons:

1. Correlation does not provide insight onto the magnitude of each event and can be strongly influenced by the presence of outliers. In this regard, numerous small deviations from the mean (i.e., weak ENSO events) can also lead to significant correlation with the SAM as long as the SAM anomalies deviate similarly through each small ENSO deviation. As noted by LachlanCope and Connolley (2006), strong ENSO forcing (i.e., an index with a high absolute value) within the tropics is necessary to generate the Rossby wavetrain pattern leading to the downstream high latitude teleconnection.

2. As demonstrated by previous studies, the ENSO-SAM correlation has strong seasonal and decadal variation (Silvestri and Vera 2003; Fogt and Bromwich 2006; L'Heureux and Thompson 2006; Stammerjohn et al. 2008). The non-stationary and relatively weak correlation between ENSO and SAM suggests the two are 
relatively independent, especially outside of austral summer, as many strong SAM events are not associated with ENSO events, and vice versa.

Therefore this study uses composite analysis to filter out weak ENSO events, examine the changes for each SAM and ENSO phase and their combinations, and ultimately more reliably investigate the South Pacific atmospheric circulation variations. It should be noted that Fogt and Bromwich (2006) obtain similar results using either method since there are numerous strong ENSO and SAM events during their study period (i.e., 1979-2001).

Composites are based on the standardized monthly Niño 3.4 SST anomalies and the SAM index. The standardization was done as follows: First, the Niño 3.4 SST anomalies were inverted in order to preserve the positive correlation between the ENSO and SAM indices, similar to that between the Southern Oscillation index and the SAM (Fogt and Bromwich 2006). Next, each monthly dataset was detrended to remove any long-term trends. Finally, means and standard deviations for each month were calculated using 1971-2000 as the base period, and these values were used to calculate the standardized anomalies by month. In turn, this gives each month equal weight and effectively removes any seasonal cycle that may be present in the raw data.

\section{Results}

\subsection{The ENSO-SAM relationship}

The joint ENSO-SAM distribution based on the standardized indices is displayed in Fig. 1. To increase the sample size and the robustness of the results, a \pm 0.5 standard deviation threshold was used to classify the data into nine distinct groups, as indicated in Fig. 1. Similar results are obtained using thresholds of 0.75 and 1 standard deviation, but the sample sizes decrease for these values. 'In phase' events are defined when both indices are outside of the 0.5 standard deviation threshold and are of the same sign; 'out of phase' events occur similarly when both indices are outside of the threshold but are of opposite sign (recall the Niño 3.4 SST anomalies have been inverted). Cases are termed 'climatology' when both monthly indices are within \pm 0.5 standard deviations, and individual events (SAM-, SAM+, La Niña (LN), and El Niño (EN)) are defined as months when only the given index lies outside of the threshold. Table 1 lists the number of months (also by season and decade) for each of the nine categories displayed in Fig. 1.

To determine if any of the counts in Table 1 are different than expected by chance, the chi-square probability

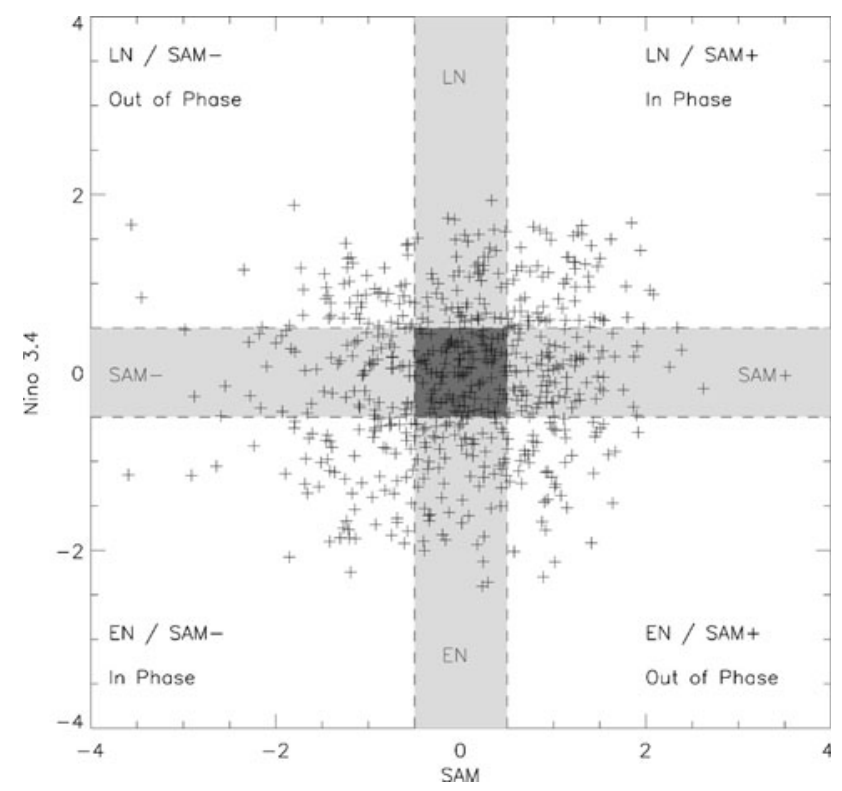

Fig. 1 Monthly ENSO-SAM standardized indices, with nine distinct regions defined based on the simultaneous sign of the two indices. The dark shaded region bounded by \pm 0.5 represents climatology. Counts in each region (and by season and decade) are given in Table 1 . The monthly data were detrended before standardization

based on a $3 \times 3$ contingency table of the joint ENSOSAM distribution (rows 1-9) is given for each column of Table 1 . The chi-squared $\left(\chi^{2}\right)$ statistic is calculated using the following formula:

$\chi^{2}=\sum_{i=1}^{3} \sum_{j=1}^{3} \frac{\left(\mathrm{O}_{i j}-\mathrm{E}_{i j}\right)^{2}}{\mathrm{E}_{i j}}$

where $i, j$ are row and column indicators, respectively, and $\mathrm{O}_{i j}$ and $\mathrm{E}_{i j}$ are the observed and expected counts, respectively, in the given cell. Expected counts are based on the marginal probabilities for each cell, which themselves are a function of the column and row totals of the $3 \times 3$ contingency table. Based on the above formula, a large chisquared value can result when any (or multiple cells) cell deviates substantially from its expected count, which in turn results in a lower probability that the null distribution of independent categories is true.

From Table 1, there are many interesting features of the joint ENSO-SAM distribution that deserve further discussion. Over the full period (1957-2009), the chi-square statistic suggests a moderately significant relationship $(p<0.10)$ between ENSO and the SAM (i.e., the two categories are not independent). This chi-square statistic arises from multiple factors: La Niña only events occur less often then expected by chance, in phase events (both La $\mathrm{Niña/SAM}+$ and El Niño/SAM-) occur much more often then expected by chance, and El Niño/SAM+ events occur less than expected by chance. All of these relationships still 
Table 1 Number of months by category used in the composites and the expected counts (italic) based on the joint standardized ENSO-SAM distribution (Fig. 1) for 1957-2009 (1979-2009 in parentheses)

\begin{tabular}{|c|c|c|c|c|c|c|c|c|c|c|c|}
\hline & Total (79-09) & DJF & MAM & JJA & SON & $50 \mathrm{~s}^{\mathrm{a}}$ & $60 \mathrm{~s}$ & $70 \mathrm{~s}$ & $80 \mathrm{~s}$ & $90 \mathrm{~s}$ & $00 \mathrm{~s}$ \\
\hline \multirow[t]{2}{*}{ SAM + only } & $88(52)$ & 24 & 19 & 23 & 22 & 4 & 26 & 12 & 11 & 18 & 17 \\
\hline & 83.07 (51.39) & 22.14 & 17.64 & 22.88 & 20.38 & 2.89 & 22.23 & 4.62 & 14.58 & 25.17 & 14.09 \\
\hline \multirow[t]{2}{*}{ SAM- only } & $69(45)$ & 17 & 20 & 21 & 11 & 3 & 11 & 12 & 17 & 11 & 15 \\
\hline & $78.50(47.00)$ & 20.47 & 20.92 & 20.19 & 16.92 & 5.06 & 14.98 & 5.14 & 15.00 & 18.98 & 15.91 \\
\hline \multirow[t]{2}{*}{ La Niña only } & $59(29)$ & 14 & 18 & 11 & 16 & 1 & 8 & 21 & 11 & 7 & 11 \\
\hline & $67.01(35.45)$ & 16.66 & 19.47 & 13.46 & 17.40 & 0.78 & 9.32 & 28.31 & 15.11 & 11.92 & 12.40 \\
\hline \multirow[t]{2}{*}{ El Niño only } & $75(47)$ & 17 & 19 & 23 & 16 & 7 & 14 & 8 & 16 & 15 & 15 \\
\hline & 71.55 (41.93) & 15.95 & 17.09 & 19.62 & 18.91 & 8.17 & 12.90 & 11.63 & 13.48 & 6.20 & 11.60 \\
\hline \multirow[t]{2}{*}{ La Niña/SAM+ } & $65(38)$ & 20 & 17 & 13 & 15 & 1 & 9 & 17 & 14 & 14 & 10 \\
\hline & $56.55(30.05)$ & 15.77 & 13.51 & 11.44 & 15.63 & 0.44 & 9.97 & 21.54 & 10.79 & 13.08 & 8.74 \\
\hline \multirow[t]{2}{*}{ El Niño/SAM- } & $67(36)$ & 19 & 17 & 13 & 18 & 11 & 11 & 9 & 7 & 19 & 10 \\
\hline & $57.06(32.51)$ & 13.96 & 14.06 & 14.71 & 14.10 & 8.17 & 9.30 & 9.86 & 9.90 & 5.14 & 9.23 \\
\hline \multirow[t]{2}{*}{ La Niña/SAM- } & $53(26)$ & 13 & 14 & 11 & 15 & 0 & 9 & 18 & 12 & 4 & 10 \\
\hline & $53.44(27.49)$ & 14.58 & 16.02 & 13.46 & 12.97 & 0.78 & 6.72 & 24.00 & 11.10 & 9.88 & 9.86 \\
\hline \multirow[t]{2}{*}{ El Niño/SAM+ } & $47(27)$ & 9 & 7 & 15 & 16 & 3 & 11 & 6 & 10 & 13 & 4 \\
\hline & $60.38(35.55)$ & 15.09 & 11.85 & 19.62 & 16.99 & 0.60 & 13.80 & 8.85 & 9.96 & 6.80 & 8.17 \\
\hline \multirow[t]{2}{*}{ Climatology } & $103(62)$ & 25 & 25 & 26 & 27 & 6 & 21 & 17 & 22 & 19 & 18 \\
\hline & $98.43(60.61)$ & 23.39 & 25.44 & 26.92 & 22.69 & 5.06 & 20.78 & 19.71 & 20.42 & 22.88 & 20.00 \\
\hline Chi-square probability ${ }^{\mathrm{b}}$ & $0.07(0.16)$ & 0.14 & 0.37 & 0.78 & 0.28 & 0.32 & 0.44 & 0.00 & 0.31 & 0.00 & 0.36 \\
\hline SAM events & $157(97)$ & 41 & 39 & 44 & 33 & 7 & 37 & 24 & 28 & 29 & 32 \\
\hline ENSO events & $134(76)$ & 31 & 37 & 34 & 32 & 8 & 22 & 29 & 27 & 22 & 26 \\
\hline In phase events & $132(74)$ & 39 & 34 & 26 & 33 & 12 & 20 & 26 & 21 & 33 & 20 \\
\hline Out of phase events & $100(53)$ & 22 & 21 & 26 & 31 & 3 & 20 & 24 & 22 & 17 & 14 \\
\hline
\end{tabular}

Also given is the chi-square probability of independence for rows 1-9 of each column, and total number of SAM, ENSO, in phase (sum of rows 5 and 6), and out of phase events (sum of rows 7 and 8 ) at the bottom of the Table

${ }^{a}$ The statistics presented for this column are based only on El Niño and SAM events since there were no La Niña events during 1957-1959

b The null distribution is approximately chi-square when the expected counts in each cell are more than 5; in other cases the null distribution may violate this approximation

exist using the 1979-2009 subset, and reinforce the positive correlation between the two datasets and the fact that La Niña events preferentially occur with SAM+ and El Niño events preferentially occur with SAM- (i.e., L'Heureux and Thompson 2006; Carvalho et al. 2005; Fogt and Bromwich 2006; Gong et al. 2010).

The seasonal variations of the ENSO-SAM relationship are examined in columns 3-6 of Table 1 and in Fig. 2, the latter showing the counts for each category by month (grey bars for 1957-2009, blue bars for 1979-2009). During the four seasons, the highest statistical relationship between ENSO and the SAM is observed during austral summer (December-February, DJF) in accord with previous studies (Fogt and Bromwich 2006; L'Heureux and Thompson 2006). As with the total counts in the first two columns of Table 1, the higher statistical relationship during DJF is dominated by the greater occurrence of in phase events than expected by chance (La Niña/SAM+ and El Niño/ $\mathrm{SAM}-$ ), and the reduced occurrence of El Niño/SAM+ events than expected by chance. Figure 2 demonstrates that the seasonality found in each individual group is broadly similar for the 1957-2009 data and for the period data from 1979 onward. Figures 2e-f also demonstrate that the in phase relationships (especially La Niña/SAM+) occur with a preference during November-February, and the El Niño/ $\mathrm{SAM}+$ out of phase combination (Fig. 2h) primarily occurs during the polar winter through mid spring, MayOctober.

The temporal evolution of ENSO-SAM relationships is examined in the final columns of Table 1 and in Figs. 3 and 4, which show the counts by year (Fig. 3) and by decade/ season (Fig. 4; Table 1) for each category. Most notable is the strong decadal variability of the ENSO- SAM relationship, with a significant $(p<0.01)$ relationship observed during the 1970s and 1990s (Table 1). The 1970s significance is brought about by the fact that more SAM only events occurred than expected by chance (top two rows of Table 1), while ENSO only (rows 3-4 of Table 1) and ENSO-SAM events (rows 5-8 of Table 1) occurred less than expected by chance. The 1990s were particularly 
Fig. 2 Counts by month for the eight categories identified in Table 1 and Fig. 1. Grey bars are for 1957-2009, blue for 1979-2009
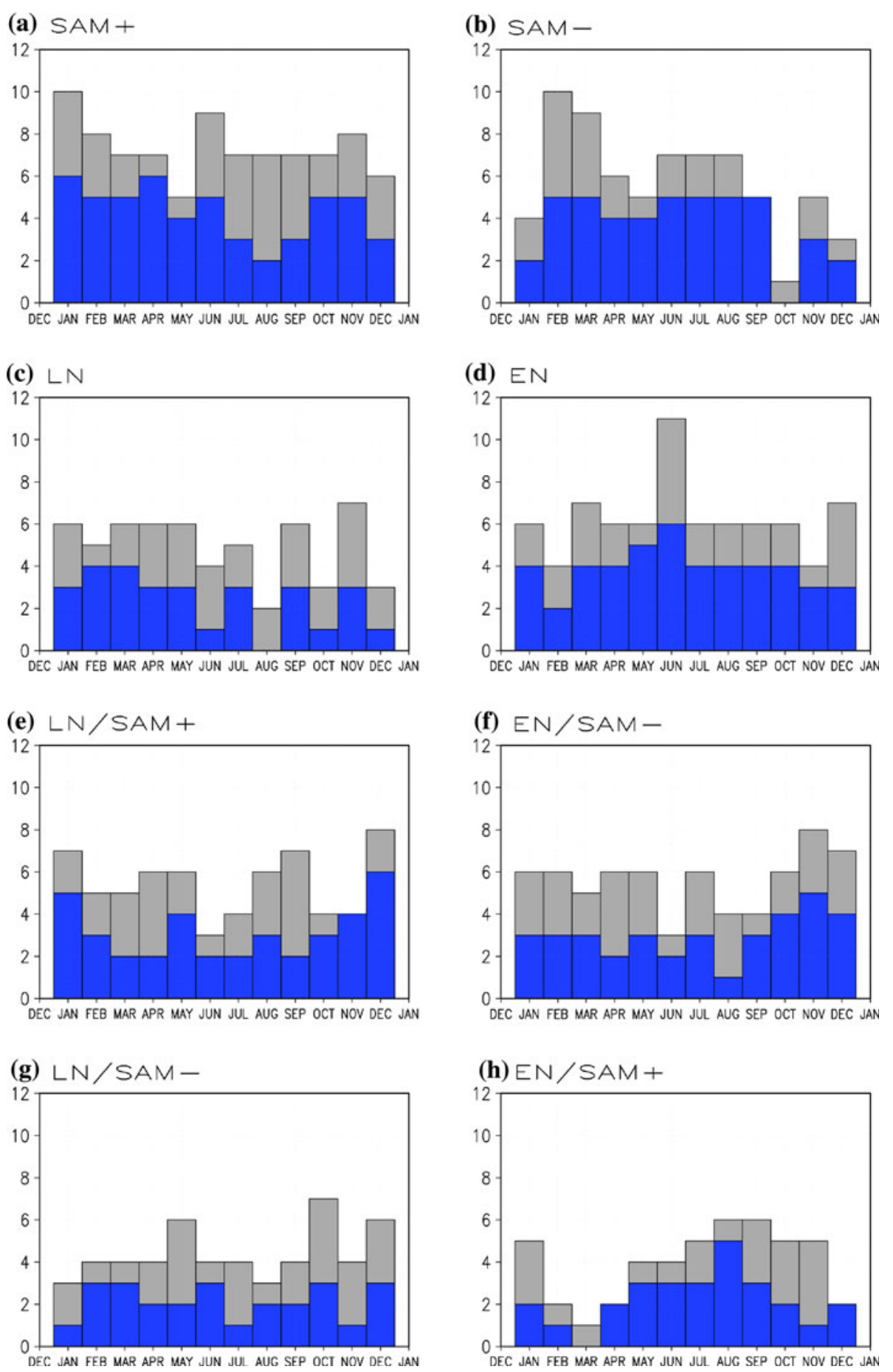

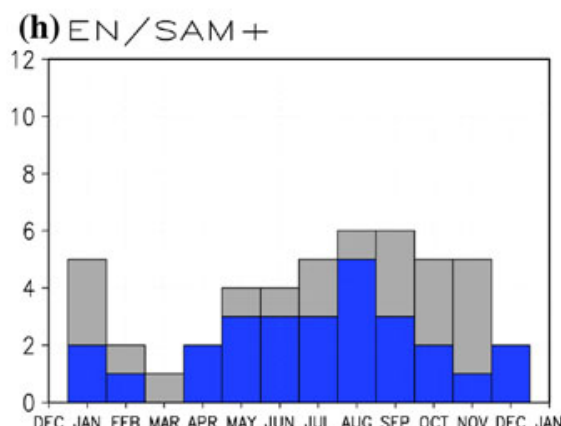

marked with the greatest occurrence of in phase events, while the 1960s and 1980s showed a greater occurrence of SAM or ENSO only events. The counts by season/decade in Fig. 4 reveal little seasonal stratification for each category, although there is a slight preference for La Niña/ SAM+ events in DJF during the 1990s (Fig. 4e), a winter (June-August, JJA) preference for out of phase events in the 1980s (Fig. 4g-h), and SAM+ and El Niño only events during the 1960s (Fig. 4a, d, respectively).
In summary, Table 1 and Figs. 2, 3, 4 support the previous work which noted seasonally and decadally dependent significant ENSO-SAM relationships, which are most marked in austral summer and during the 1990s (Silvestri and Vera 2003; Carvalho et al. 2005; Fogt and Bromwich 2006; L'Heureux and Thompson 2006). We also note here a significant relationship between ENSO-SAM during the 1970s associated with a large number of SAM only events that occurred more often than expected by chance and joint 
Fig. 3 Counts by year for the eight categories identified in Table 1 and Fig. 1
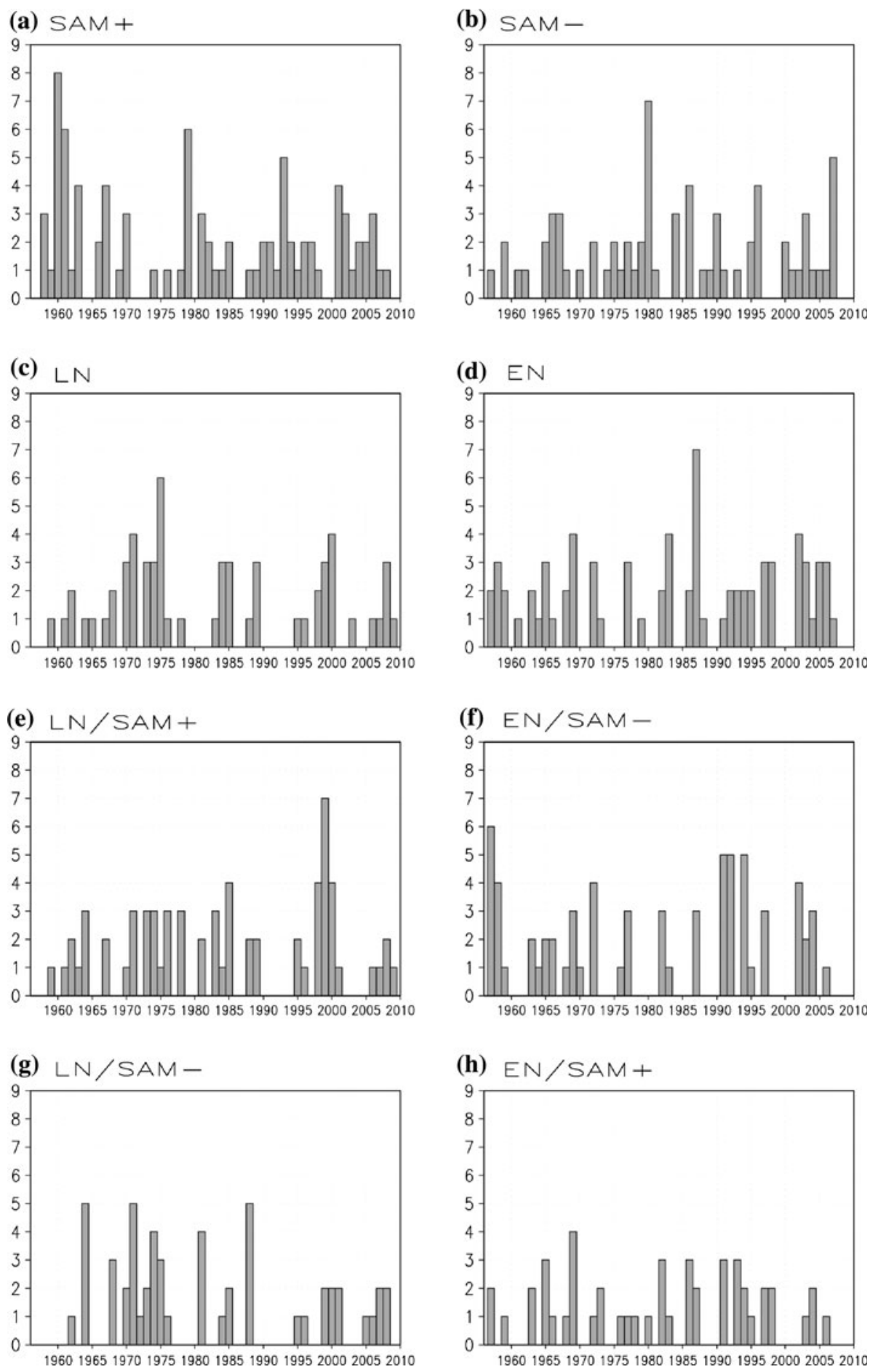

(h) $\mathrm{EN} / \mathrm{SAM}+$

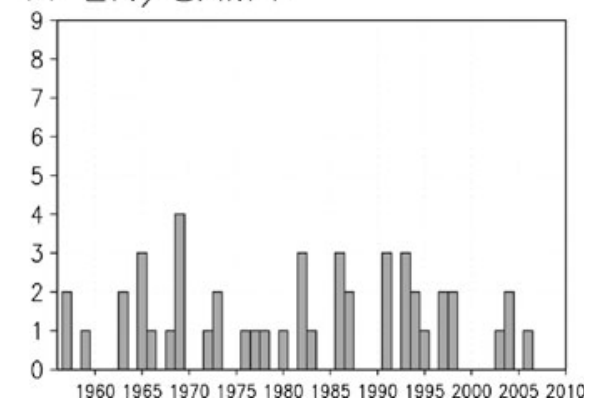

ENSO-SAM events that occurred less often than expected by chance. While these results agree with previous studies, it is important to remember that this seasonal and decadal cycle is an underlying feature of the composites examined in the following section. Although Figs. 3, 4 show important temporal fluctuations in the ENSO-SAM relationship, they also demonstrate that composites based on the monthly counts in Table 1 are comprised of many independent events and not from only one ENSO cycle, for example. The use of the full period, January 1957-February 2009, in the composites in the following section is necessary in order to increase the length of record so significant changes in the ENSO teleconnection strength can be determined (Sterl et al. 2007). 
Fig. 4 Counts by season and decade for the eight categories identified in Table 1 and Fig. 1
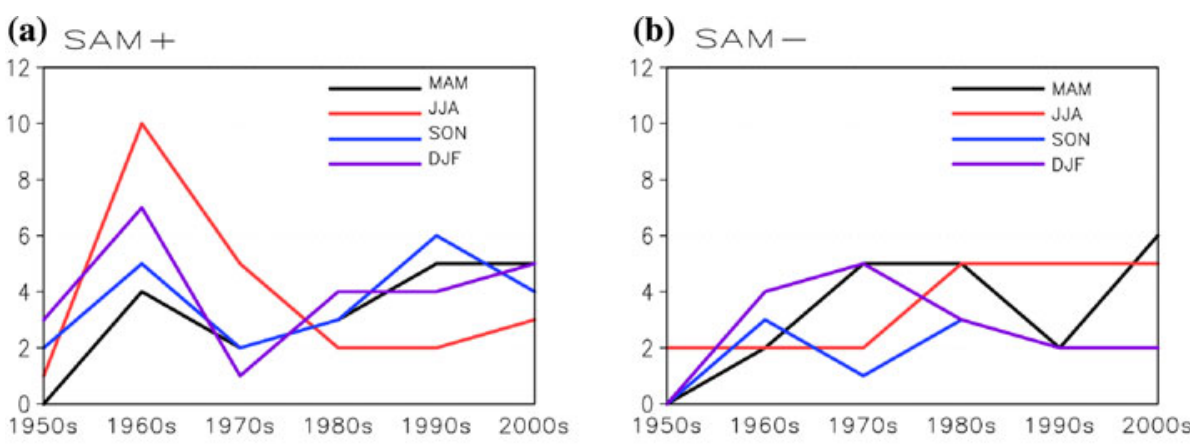

(c) $L N$

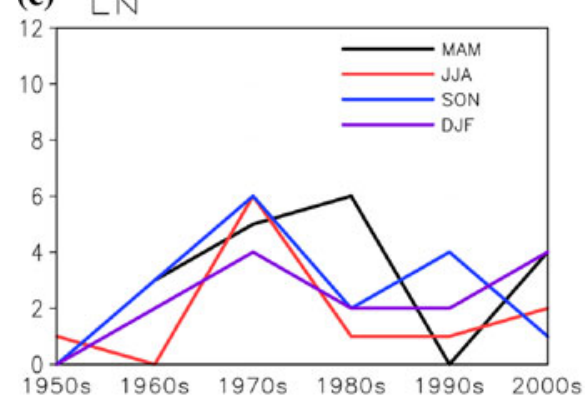

(d) $E N$

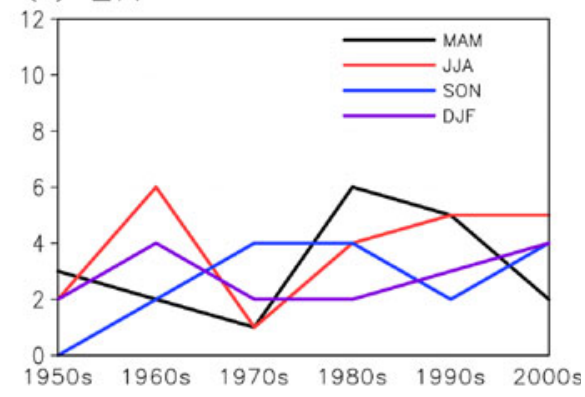

(e) $L N / S A M+$

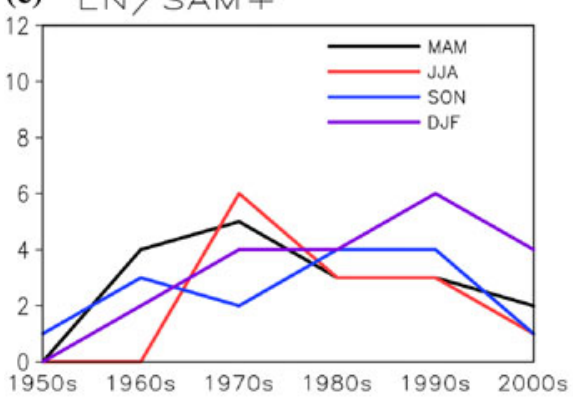

(f) $E N / S A M-$

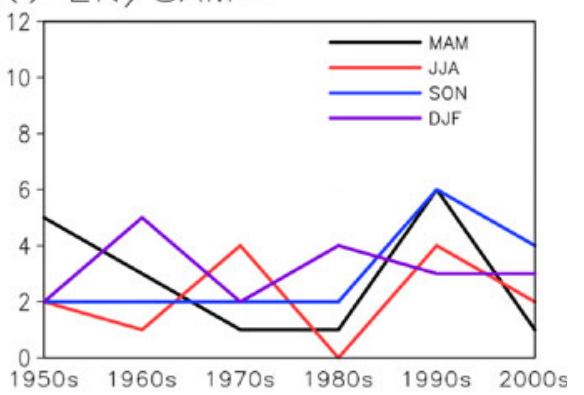

(h) $E N / S A M+$

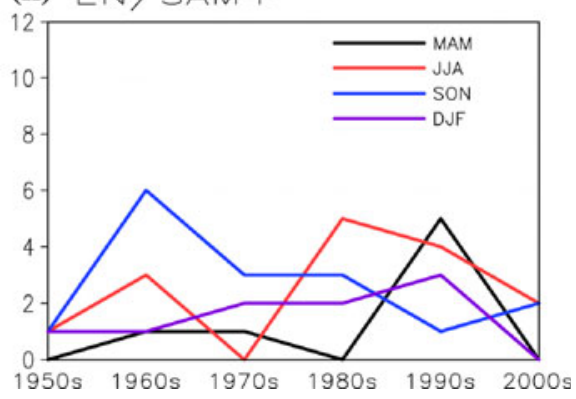

3.2 South Pacific atmospheric circulation anomalies during ENSO/SAM events

MSLP anomaly composites based on HadSLP2 for the eight categories vs. climatology in the total column of Table 1 are shown in Fig. 5. Shaded regions in the composites denote anomalies significantly different from climatology at the $p<0.05$ level based on the modified false discovery rate of Ventura et al. (2004). This statistical technique is more conservative than shading regions which reject the null hypothesis and has the further benefit of attaining global significance at the same $p$ level when at least one null hypothesis is rejected. Composites based on the NCEP reanalysis MSLP for 1957-2009 are shown in Fig. 6. The similarity between Figs. 5 and 6 provides credence that the results are robust, especially since NCEP reanalysis assimilates additional data independent of HadSLP2. To further demonstrate that the potentially less 
Fig. 5 HadSLP2 minus climatology anomaly composites for the eight categories identified in Table 1 and Fig. 1. a SAM+ only; b SAM- only; c La Niña only; d El Niño only; e La Niña/ $\mathrm{SAM}+; \mathbf{f} \mathrm{El} \mathrm{Niño/SAM}-; \mathbf{g} \mathrm{La}$ Niña/SAM-; h El Niño/ $\mathrm{SAM}+$. Contour interval is $1 \mathrm{hPa}$. Shaded regions (red positive, blue negative) are statistically different from zero at the $p<0.05$ level based on the modified false discovery rate of Ventura et al. (2004)

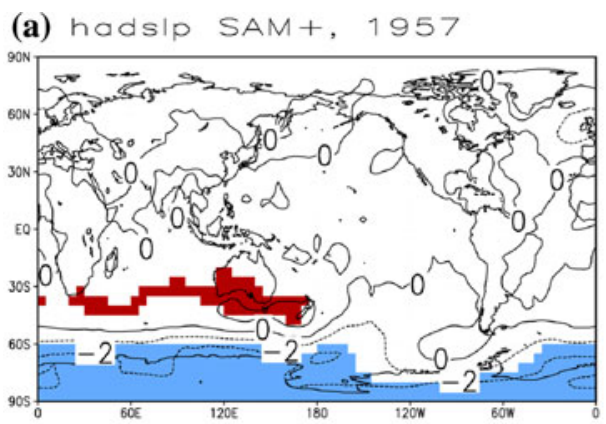

(b) hadsIp SAM-, 1957

(c) hadsip LN, 1957
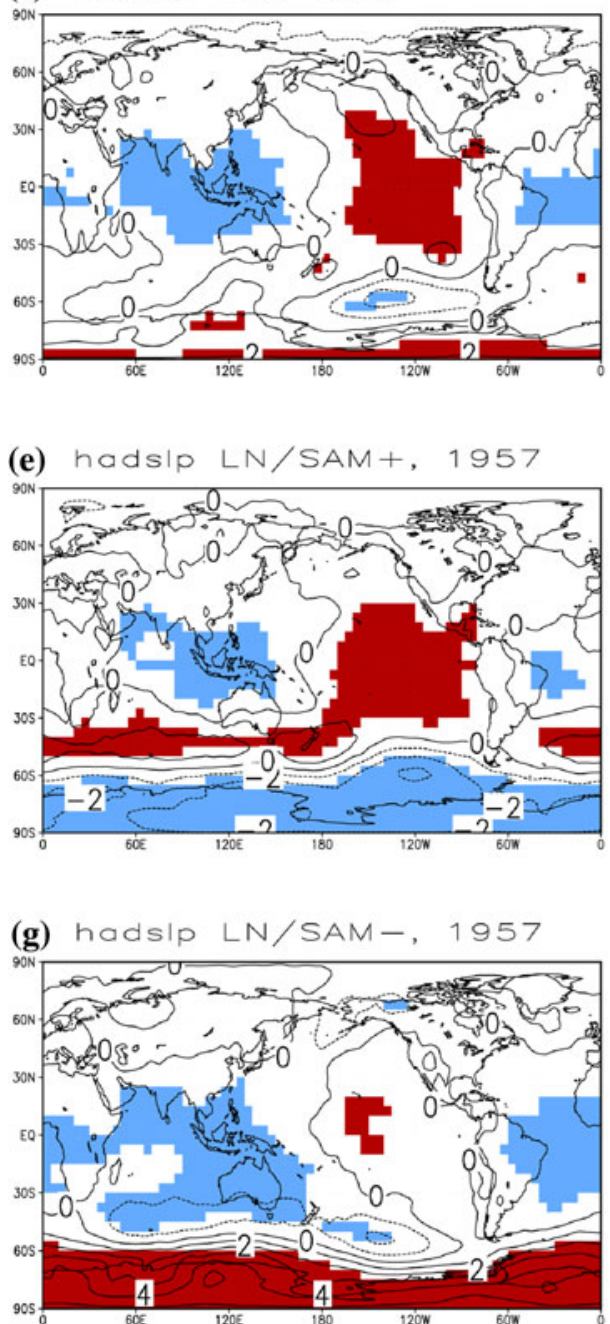

(d) hadslp EN, 1957

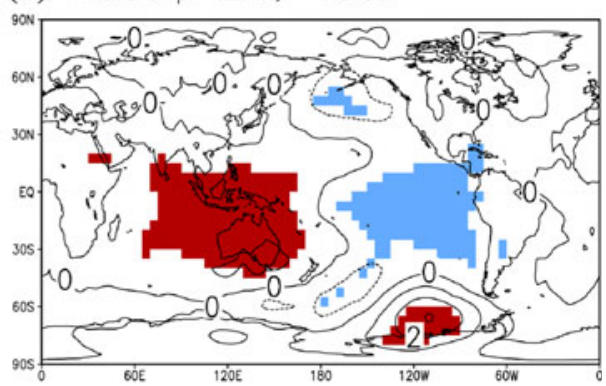

(f) hadslp EN/SAM-, 1957

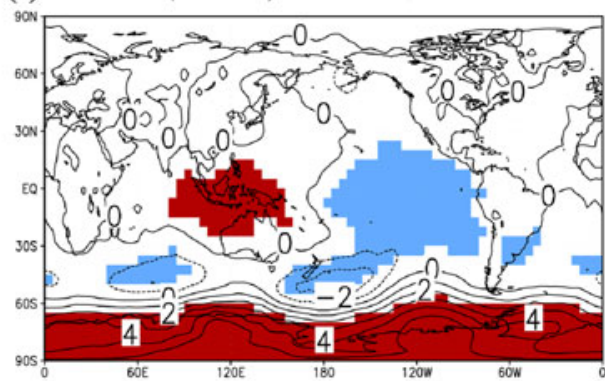

(h) hadsIp EN/SAM+, 1957
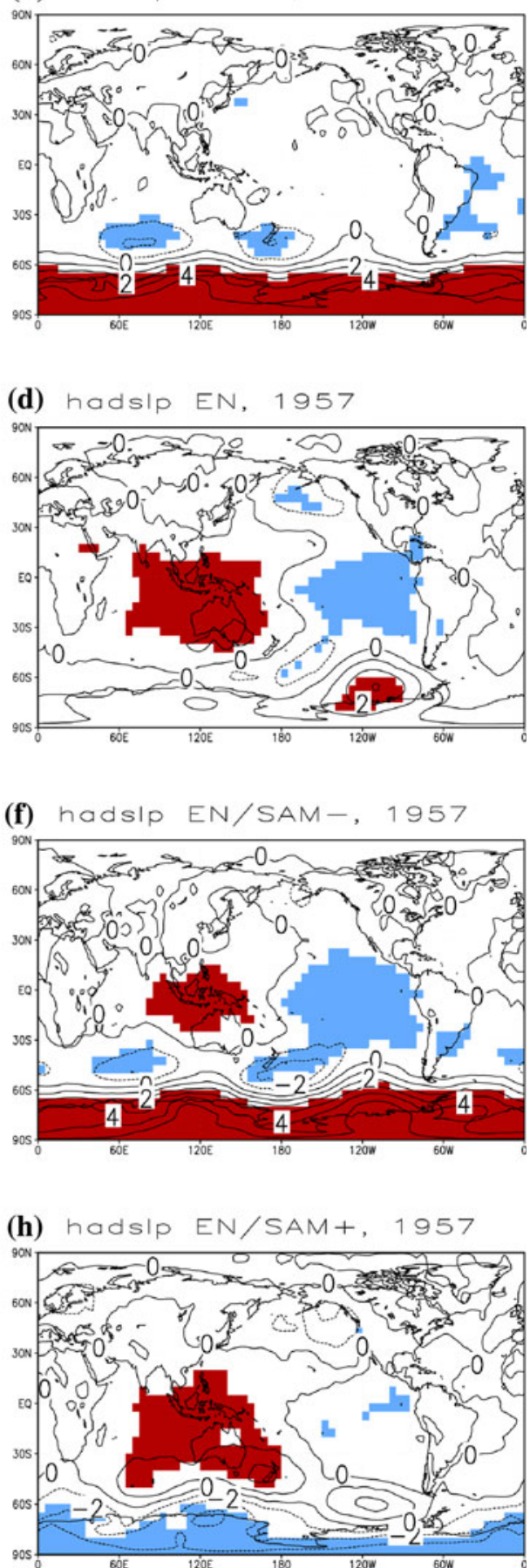

reliable early NCEP data are not significantly influencing our main conclusions, composites for HadSLP2 and NCEP MSLP for the 1979-2009 period are shown in Figs. 7, 8, respectively. Because of the similarity between Figs. 5, 6, 7,8 in terms of pattern and regions of significance, our discussion will focus on Figs. 5, 6 only throughout.

The top two rows in Figs. 5 and 6 show the SAM-only and ENSO-only patterns for reference. Recall that by definition, SAM only (ENSO only) composites tease out as best as possible anomalies from ENSO (SAM) events, as they include only the months when the given index is outside the 0.5 standard deviation threshold while the other index is weak and inside the threshold (Fig. 1). For the SAM only composites, a slight zonal asymmetry exists near the Antarctic Peninsula south of $60^{\circ} \mathrm{S}$, most marked during SAM+ only events (Figs. 5a, 6a). Meanwhile, the ENSO only composites show a much more zonally asymmetric pattern with an east-west pressure anomaly in the 
Fig. 6 As in Fig. 5, but based on MSLP from the NCEP/ NCAR reanalysis

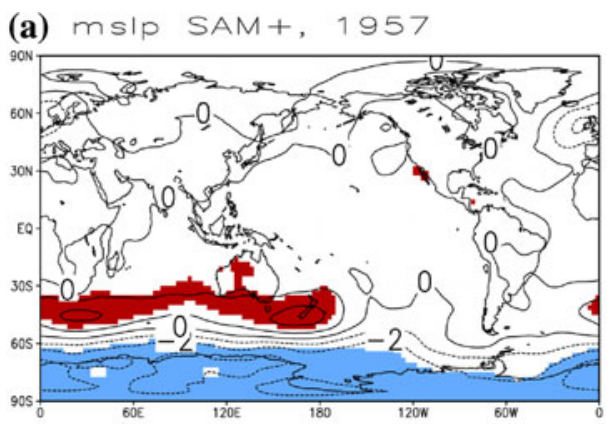

(b) $\mathrm{msip} \quad \mathrm{SAM}-, 1957$

(c) $m \operatorname{sip} L N, 1957$

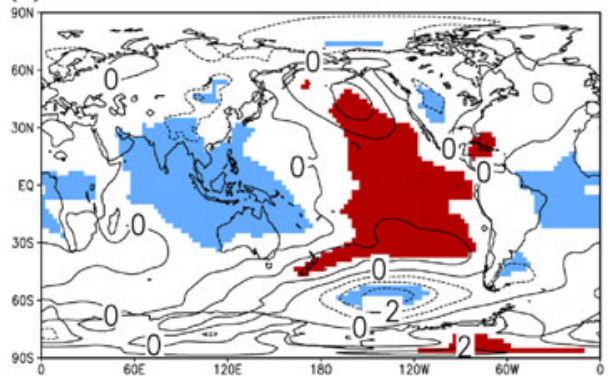

(e) $\mathrm{mslp} L \mathrm{~N} / \mathrm{SAM}+, 1957$

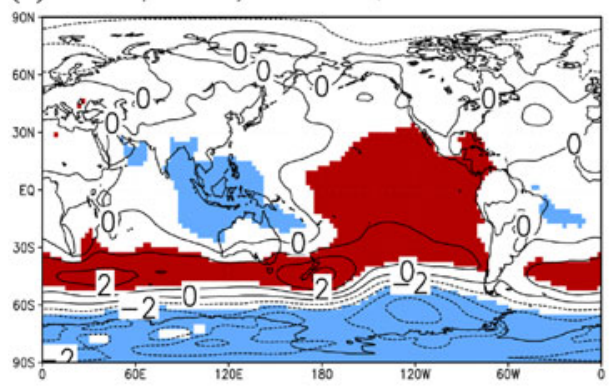

(g) $\mathrm{mslp} L \mathrm{~N} / \mathrm{SAM}-, 1957$

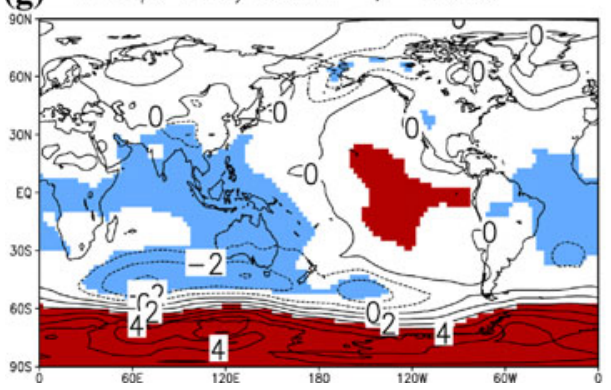

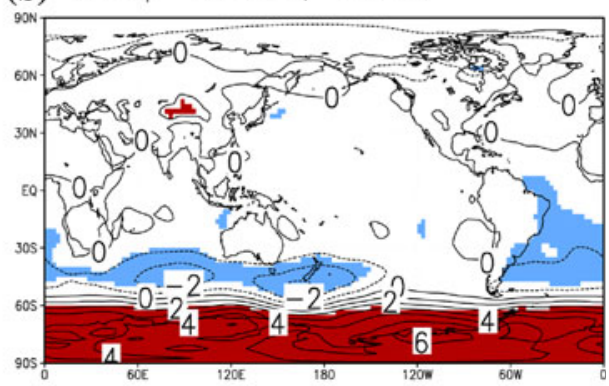

(d) $m$ slp EN, 1957

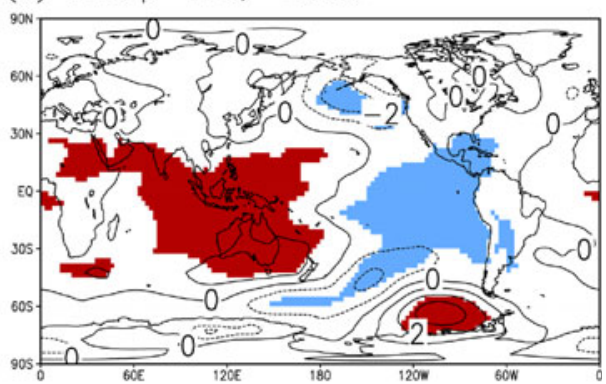

(f) $m s I p E N / S A M-, 1957$

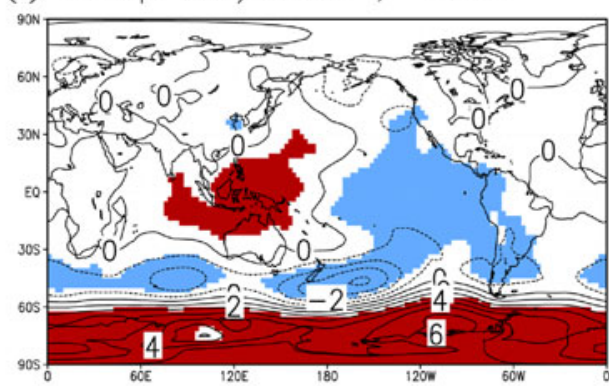

(h) $m s / p \quad E N / S A M+, 1957$

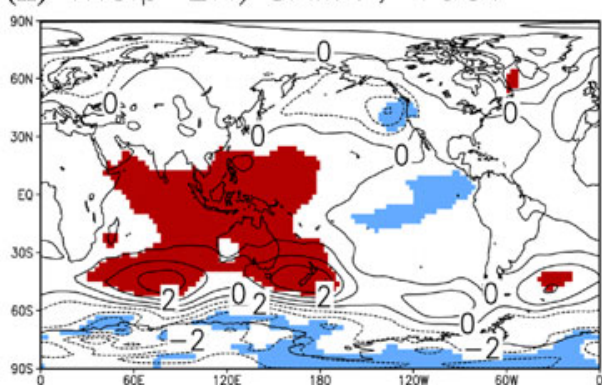

Tropics, the defining characteristic of the Southern Oscillation (Trenberth and Caron 2000), and with a teleconnection center in the South Pacific (defined hereafter as the region bounded by $\left.45^{\circ}-70^{\circ} \mathrm{S}, 150^{\circ}-70^{\circ} \mathrm{W}\right)$. This South Pacific ENSO teleconnection is statistically different $(p<0.05)$ than climatology and clearly visible in both Figs. 5c-d and 6c-d. Based on the 1979-2009 data, the La Niña teleconnection in the South Pacific is statistically different than climatology at the $p<0.10$ level.
In Figs. 5e and 6e, when La Niña occurs with positive SAM, the structure inferred during SAM and ENSO only events is retained and the anomalies in the South Pacific ENSO teleconnection remain statistically significant and at approximately the same location. Similar, but opposite, conditions are found in the El Niño/SAM- composite (Figs. 5f, 6f). The simultaneous occurrence of strong ENSO and SAM events creates a more pronounced response in the South Pacific compared to SAM only events, and resembles 
Fig. 7 As in Fig. 5, but for the 1979-2009 period
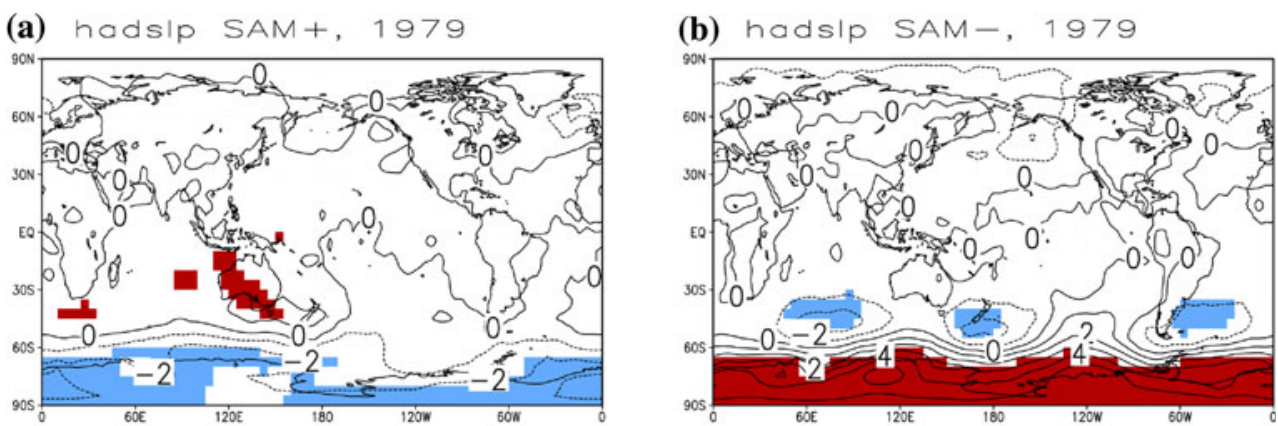

(c) hadslp LN, 1979

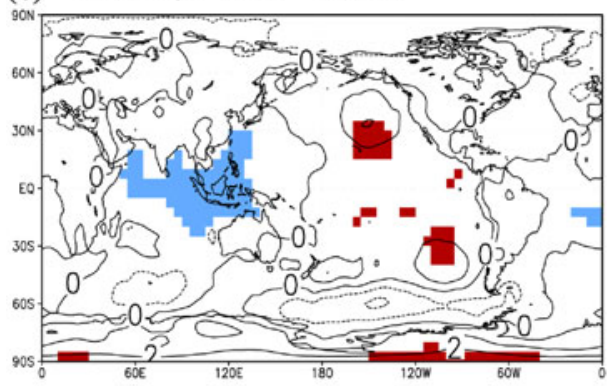

(e) hadslp LN/SAM+, 1979

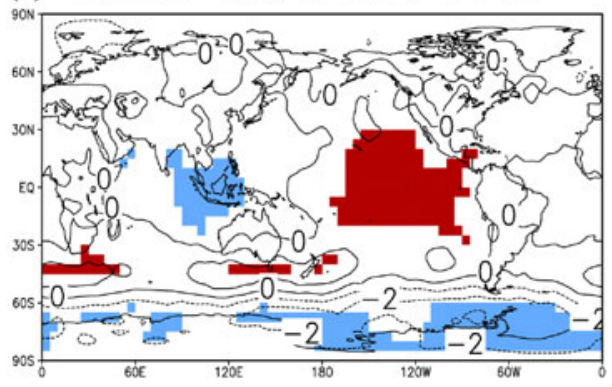

(g) hadsip LN/SAM-, 1979

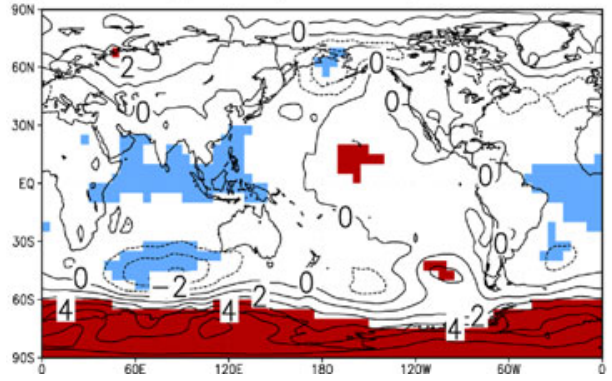

(d) hadslp EN, 1979

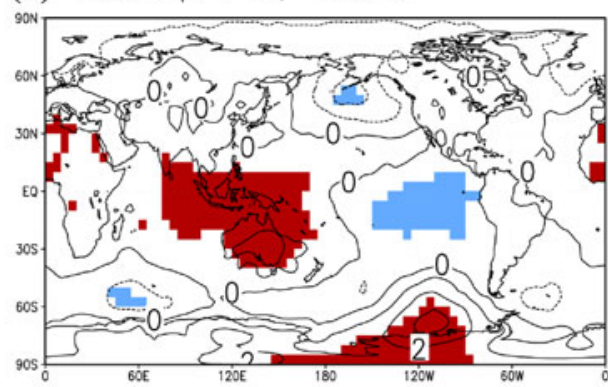

(f) hadsip EN/SAM-, 1979

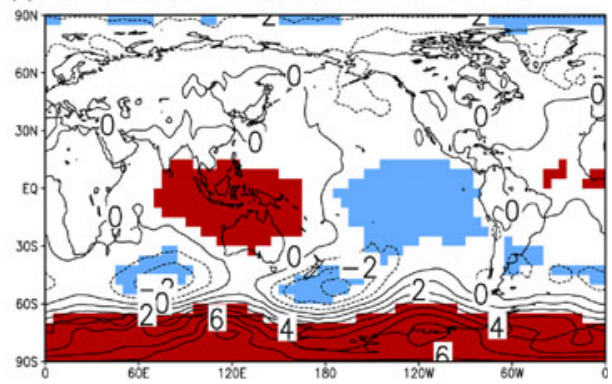

(h) hadsIp EN/SAM+, 1979

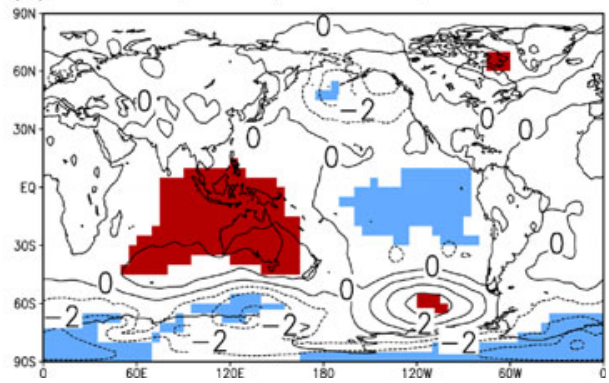

circulation anomalies that would be expected from a linear sum of the SAM and ENSO only events. However, the South Pacific pressure anomalies are notably different when the two modes are out of phase (Figs. $5 \mathrm{~g}-\mathrm{h}, 6 \mathrm{~g}-\mathrm{h}$ ): in the South Pacific the expected SAM-induced anomalies (inferred from Figs. 5a-b, 6a-b) are shifted much closer to the Antarctic coast, while the expected ENSO teleconnection (inferred from Figs. 5c-d, 6c-d) is also shifted and considerably weaker. In the El Niño out of phase case
(Figs. 5h, 6h), positive pressure anomalies are observed near the Antarctic Peninsula, although they are shifted equatorward compared to El Niño-only events in Figs. 5d and $6 \mathrm{~d}$ and are no longer significant at $p<0.05$. For the 1979-2009 data in the El Niño out of phase case (Figs. 7h, $8 \mathrm{~h}$ ), a small region of the positive pressure anomalies in the South Pacific achieve significance at $p<0.05$, but the significant region is much less compared to the El Niño alone case (Figs. 7d, 8d). Overall, Figs. 5 and 6 indicate 
Fig. 8 As in Fig. 5, but for the 1979-2009 period based on MSLP from the NCEP/NCAR reanalysis
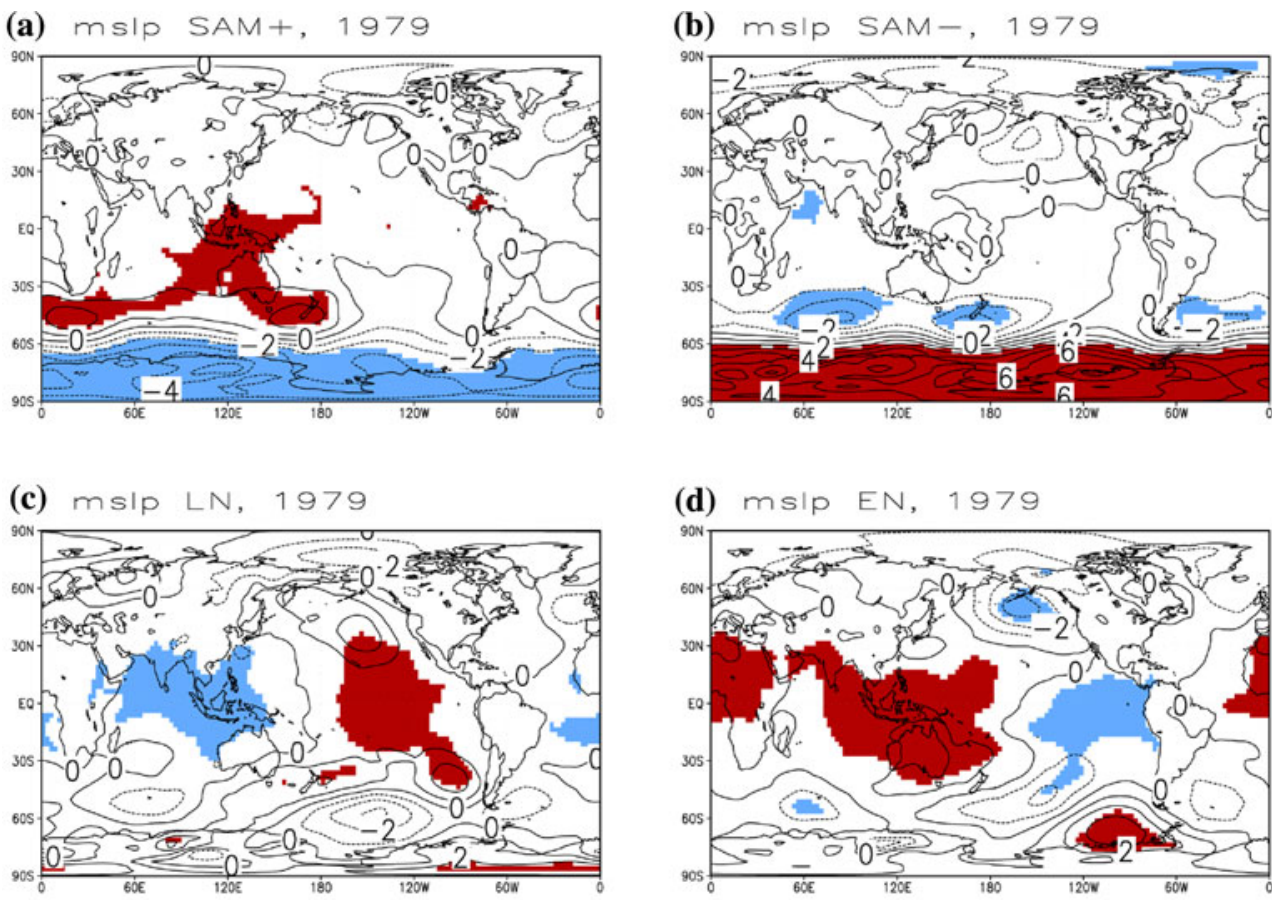

(e) $m$ sip $L N / S A M+, 1979$
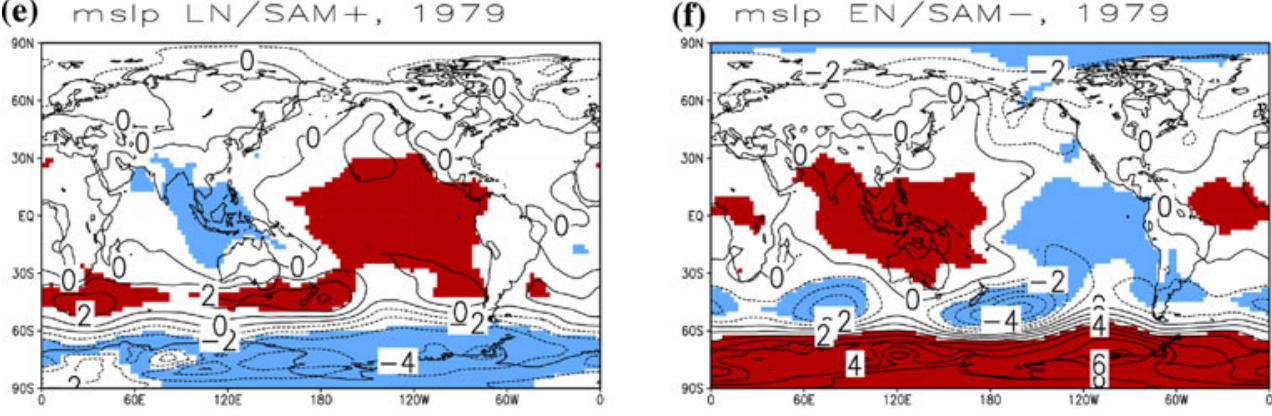

(g) $m s / p L N / S A M-, 1979$

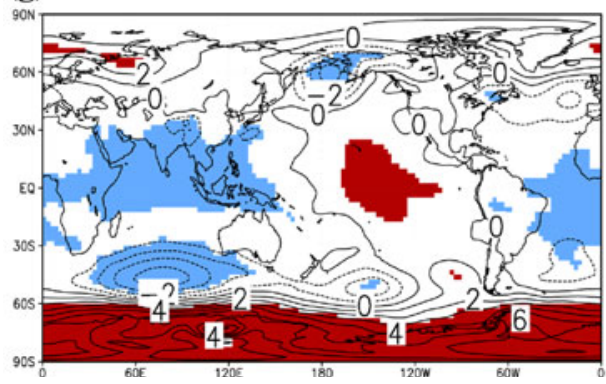

(h) $\mathrm{mslp} E N / \mathrm{SAM}+, 1979$

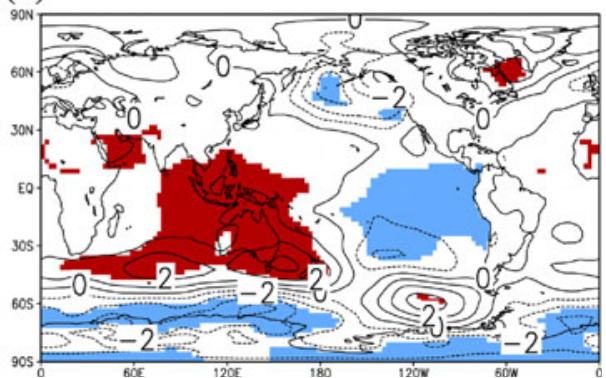

that out of phase cases have notably different anomaly patterns in the South Pacific compared to the ENSO and SAM only composites, while the in phase cases maintain signatures observed during both ENSO and SAM only events in the South Pacific.

To further consider the influence of the SAM on the ENSO teleconnection, we investigate the zonal asymmetry associated with ENSO events by exploring the Southern Hemisphere Rossby wavetrains. Since the ENSO extratropical wavetrains are more clearly visible in the zonally asymmetric flow, while the SAM appears primarily in the zonally symmetric flow (Figs. 5a-b, 6a-b), we remove the zonal mean to highlight changes in the former. Figure 9 displays composites of the $500 \mathrm{hPa}$ streamfunction zonal anomalies for the eight categories, with the shading denoting regions where the zonal anomalies exceed two standard deviations from the zonal mean. As described earlier, zonally asymmetric anomalies are seen 
Fig. 9 As in Fig. 5, but for NCEP 500 hPa streamfunction zonal anomalies. Contour interval is $0.5 \mathrm{~m}^{2} \mathrm{~s}^{-2}$. Shaded regions (red positive, blue negative) highlight zonal anomalies that exceed two standard deviations from the zonal mean
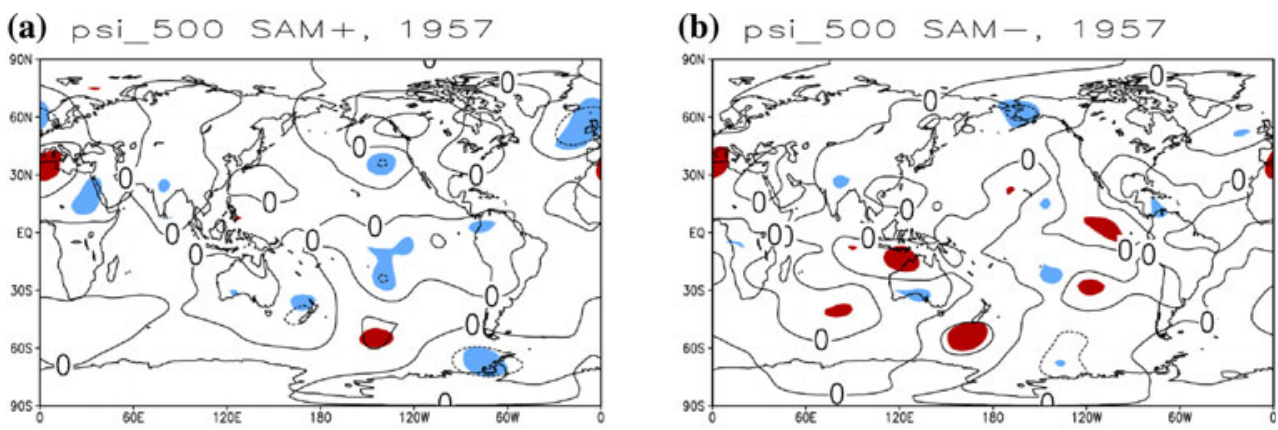

(c) psi_500 LN, 1957

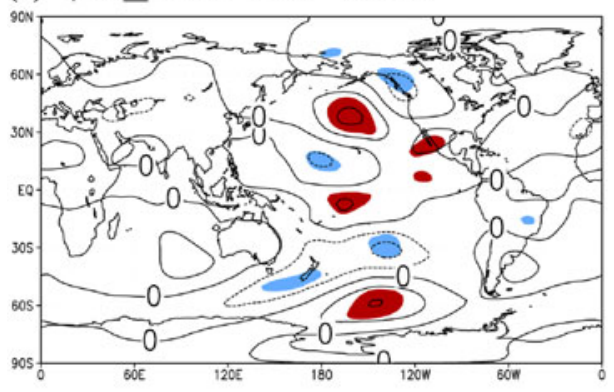

(d) psi_500 EN, 1957

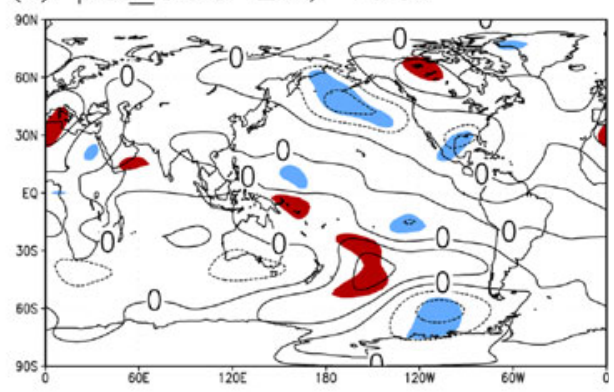

(f) psi_500 EN/SAM-, 1957

(e) psi_500 LN/SAM+, 1957
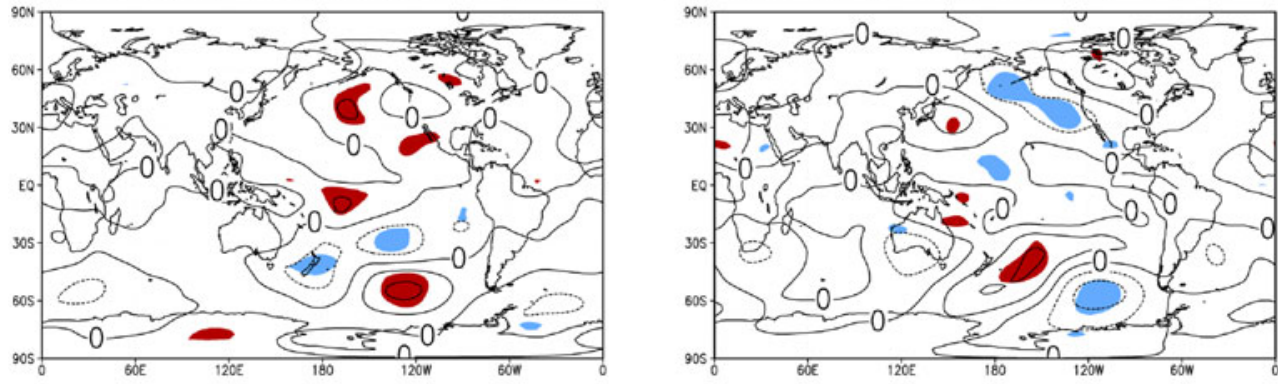

(h) psi_500 EN/SAM+, 1957

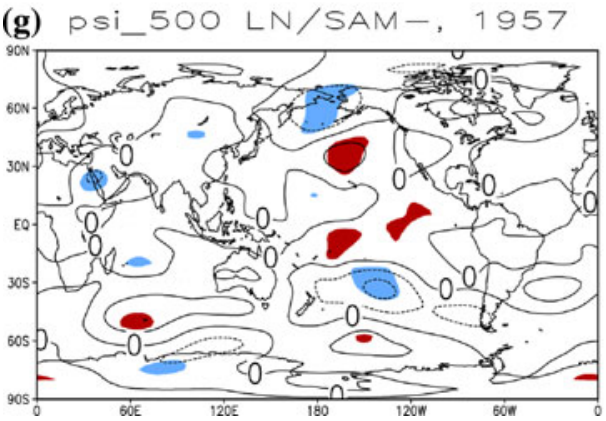

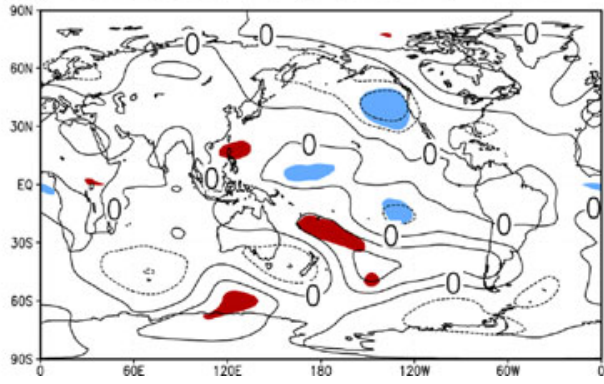

near the Antarctic Peninsula in SAM+ only events (Fig. 9a), while SAM- displays little zonal asymmetry poleward of $60^{\circ} \mathrm{S}$. Notably, this zonal asymmetry in $\mathrm{SAM}+$ disappears when using a 1.0 standard deviation threshold. Meanwhile, the Pacific North and South American pattern wavetrains are clearly visible in the Pacific Sector in Fig. 9c-d, and are similarly maintained when the two modes are in phase (Fig. 9e, f). When the two modes are out of phase (Fig. 9g, h), the Pacific South American pattern is considerably weaker, suggesting as before that the opposing strong SAM event reduces the downstream signal of ENSO events. The dynamic mechanisms behind this interaction are explored in Sect. 3c.

An additional diagnostic to quantitatively examine the changes in the ENSO teleconnection magnitude in the South Pacific is given in Fig. 10. Here, the area averaged MSLP and $500 \mathrm{hPa} / 300 \mathrm{hPa}$ geopotential height anomalies in the South Pacific [again defined as $45^{\circ}-70^{\circ} \mathrm{S}$, 
(a) LN 1957-2009 Anomalies

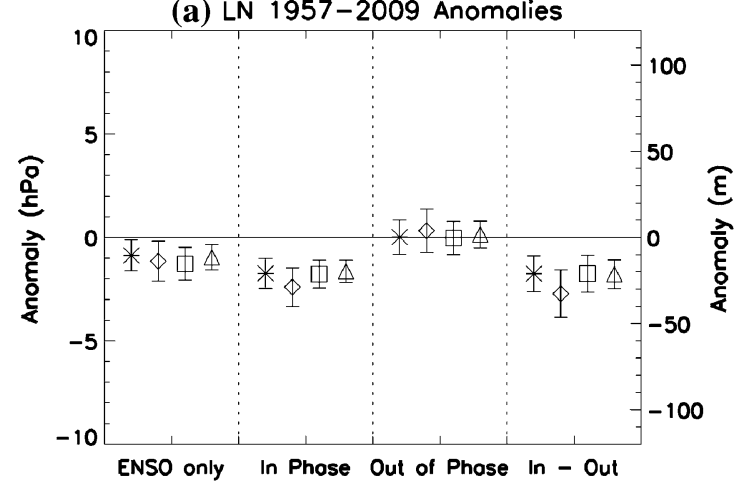

(c) LN 1979-2009 Anomalies

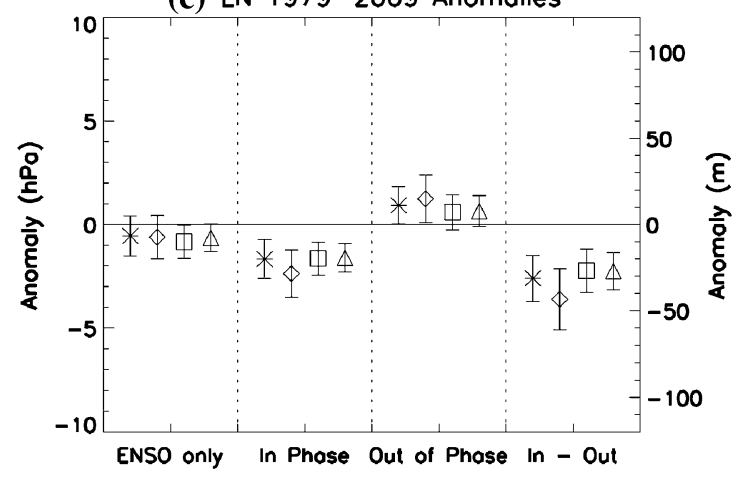

(b) EN 1957-2009 Anomalies

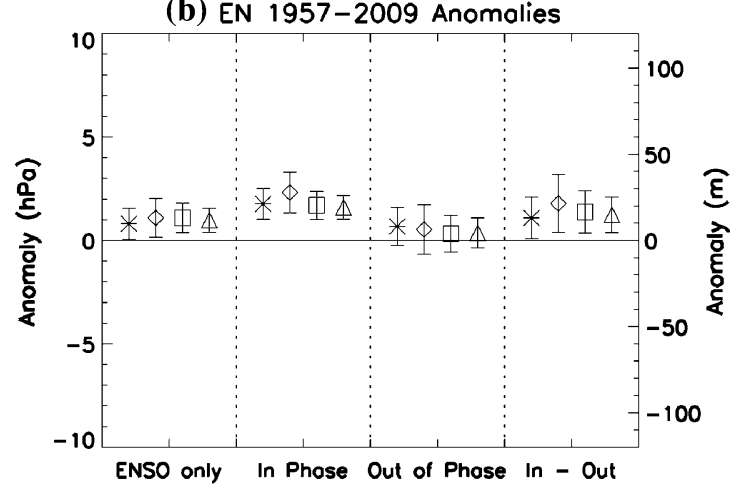

(d) EN 1979-2009 Anomalies

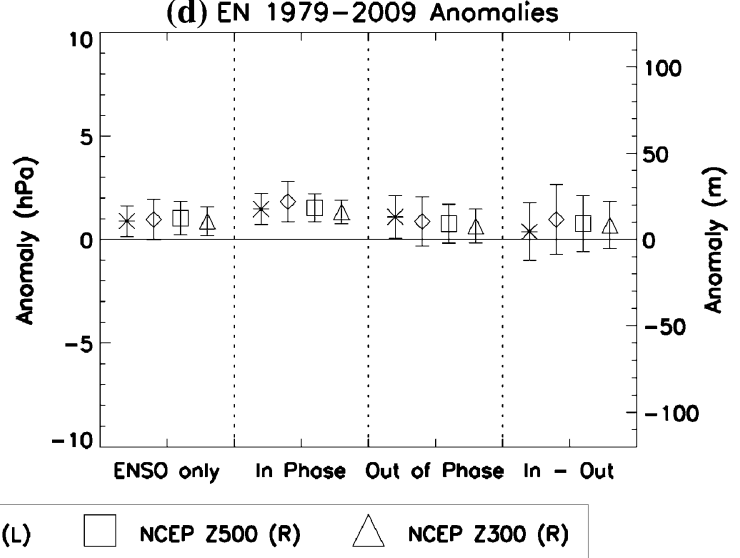

Fig. 10 Differences in the means and 95\% confidence intervals of the anomalies in the South Pacific $\left(45^{\circ}-70^{\circ} \mathrm{S}, 150^{\circ}-70^{\circ} \mathrm{W}\right)$ for HadSLP2 and NCEP MSLP (left axis), and NCEP 500 and $300 \mathrm{hPa}$ (right axis)

$\left.150^{\circ}-70^{\circ} \mathrm{W}\right]$ and the associated $95 \%$ confidence intervals for ENSO events are presented, based on the sign of the simultaneous SAM index, for the entire period and 1979 onward. The overall similarity between the top and bottom rows of Fig. 10 again demonstrates that any conclusions based on the earlier data are not influenced by potential uncertainties in the reanalyses or by a specific time period.

Within each panel of Fig. 10, the leftmost data represent the pressure and height changes in the South Pacific during ENSO only (i.e., the SAM index is weak and within \pm 0.5 standard deviations) events compared to climatology. As expected from Figs. 5c-d, La Niña (El Niño) is associated with lower (higher) pressures/heights in the South Pacific. When ENSO is in phase with the SAM (second group of data in each panel of Fig. 10), the influence of the SAM makes the pressures/heights lower (higher) than during individual La Niña (El Niño) events. Although not statistically different from the individual ENSO events, the anomalies during in phase events remain significantly different than climatology in all cases. In contrast, when ENSO is out of phase with the SAM (the third group in the panels of Fig. 10), the pressures/heights in the South for various ENSO-SAM combinations versus climatology. a La Niña events, 1957-2009; b El Niño events, 1957-2009; c La Niña events, 1979-2009; d El Niño events, 1979-2009

Pacific no longer show a statistically significant response for all data groups. For La Niña events, the conflicting influence of the negative SAM removes the expected $\mathrm{La}$ Niña response of negative anomalies, giving rise to nearzero anomalies or positive anomalies (based on data starting in 1979, Fig. 10c). For the El Niño/SAM+ case (third group in Figs. 10b, d), the influence of the positive SAM (inferred from Figs. 5a, 6a) weakens the expected South Pacific positive El Niño pressure/height anomalies, and although still positive, they are no longer statistically significant at $p<0.05$. The contrasting effects on the ENSO teleconnections in the South Pacific from the two SAM phases are readily apparent in the rightmost columns of Fig. 10. Here, the South Pacific pressures/heights are significantly different $(p<0.05$ for most variables/observations) between in phase and out of phase ENSO-SAM combinations, except for the El Niño data after 1979. This makes the South Pacific atmospheric pressure lower when strong La Niña events occur with a positive SAM, compared to months when a strong La Niña event occurs with a negative SAM. Opposite effects are observed for El Niño events, although the impact is much weaker and not significant based on data starting in 1979 (in agreement with 
the small region of significant El Niño teleconnection in Figs. 7h, 8h).

Thus, the phase and magnitude of the SAM strongly impact the magnitude of the expected ENSO response in the South Pacific. Teleconnections where the anomalies are significantly significant at $p<0.05$ are only observed when ENSO events occur with weak SAM events (i.e., $\mid S A M$ index $\mid<0.5$ standard deviations) or when a La Niña occurs with a SAM+ and an El Niño occurs with a SAM-. In other cases, the South Pacific ENSO teleconnection is weakened and no longer statistically significant. The impacts appear most strongly for La Niña events, where the impact of an opposing SAM- event generates near-zero or positive pressure anomalies in the South Pacific, thereby leading to dramatic differences in the pressure/height anomalies for in phase vs. out of phase cases.

\subsection{Mechanisms leading to South Pacific atmospheric circulation variations}

Having established the significant influence SAM events can have on the high latitude ENSO teleconnection, we now turn to understanding the mechanisms behind this alteration. We build the case by first examining the zonal mean zonal wind anomaly composites in Fig. 11, along with the anomalous meridional circulation vectors and resulting Coriolis torque, $f[\bar{v}]$, acting on the anomalous meridional wind. Here, the square brackets refer to the zonal average, the over bar to monthly means. Since there are only minor changes between the full analysis (1957-2009) and the recent analysis (1979-2009) (Figs. 5, $6,7,8)$, we only consider the latter to reduce any potential uncertainty from the reanalyses.

With the strengthened meridional pressure gradient, $\mathrm{SAM}+$ only events are associated with stronger circumpolar westerly flow between $50^{\circ}-70^{\circ} \mathrm{S}$ (Fig. 11a); opposite conditions are observed for SAM- only events (Fig. 11b). As observed by Thompson and Wallace (2000), SAM positive (negative) events are also associated with anomalous rising (sinking) motion poleward of $60^{\circ} \mathrm{S}$, and sinking (rising) motion in the midlatitudes between $40^{\circ}-50^{\circ} \mathrm{S}$. The dominant meridional circulation impacts from ENSO only events (Fig. 11c-d) are a weakened (strengthened) Hadley cell during La Niña (El Niño), with a resulting weakening (strengthening) of the subtropical jet due to the conservation of angular momentum. However, there are also zonal mean circulation anomalies in the extratropics during ENSO only events, as noted by L'Heureux and Thompson (2006). These include a strengthening of the zonal winds at $50^{\circ} \mathrm{S}$ during La Niña, and changes to the Ferrell Cell that resemble those during SAM+ events. Nearly opposite anomalous conditions are observed during El Niño events, although the negative zonal wind anomalies are located further poleward and are weaker $\left(60^{\circ} \mathrm{S}\right.$ in Fig. $11 \mathrm{~d}$ compared to $50^{\circ} \mathrm{S}$ in Fig. 11c). Due to the similarity between the SAM+ and La Niña composites, when the two occur simultaneously as in Fig. 11e, features of both events are present, and the overall circulation anomalies are stronger. This is also true for months when El Niño occurs with a SAM- (Fig. 11f). The preservation of both ENSO and SAM features is furthermore consistent with the single level pressure/height anomalies presented in Figs. 5, 6, 7, 8, 9. Together, the zonal mean circulation anomalies in Fig. 11a-f again suggest the anomalous zonal mean circulations induced separately by each mode (Fig. 11a-d) reinforce rather than oppose each other when combinations of La Niña/SAM+ or El Niño/SAM- occur. Figures 11g-h show, however, that when La Niña/SAMor El Niño/SAM+ combinations occur, the meridional circulation anomalies associated with each event individually (Fig. 11a-f) oppose each other, leading to weaker anomalies in the zonal mean zonal wind and overall meridional circulation (especially in the Hadley cell) in these out of phase combinations.

In each panel of Fig. 11, in the upper troposphere poleward of $30^{\circ} \mathrm{S}$ the Coriolis torque resulting from the anomalous meridional circulation induces a zonal wind forcing which opposes the zonal wind anomalies. This finding was observed by previous studies (i.e., Thompson and Wallace 2000; Seager et al. 2003; L'Heureux and Thompson 2006). In order to maintain the zonal wind anomalies present in Fig. 11, anomalous meridional eddy momentum flux convergence must occur (Trenberth 1986, 1991; Seager et al. 2003; L'Heureux and Thompson 2006). We demonstrate that this is the case by plotting the anomalous transient momentum flux convergence with the zonal wind anomalies in Fig. 12. The use of transient (here represented with primes and calculated as the 6-hourly departure from the monthly mean) rather than stationary eddies (departures from the zonal mean) is justified since transient eddies dominate over stationary eddies in the Southern Hemisphere as standing wave patterns created by topographic barriers are much weaker than in the Northern Hemisphere (Oort and Peixoto 1983; Limpasuvan and Hartmann 1999; Seager et al. 2003).

From Fig. 12, it is clear that the extratropical (poleward of $30^{\circ} \mathrm{S}$ ) anomalous zonal winds are due primarily to the anomalous transient eddy momentum flux convergence/ divergence (thick contours in Fig. 12). The maximum of zonal wind anomalies is often slightly meridionally displaced due to the opposing forcing from the Coriolis torque as displayed in Fig. 11. A similar result was obtained by L'Heureux and Thompson (2006) at $300 \mathrm{hPa}$; we expand this here by showing that the eddy-mean flow interactions with each of these terms are valid for the entire troposphere above $500 \mathrm{hPa}$. Further, the eddy-mean flow interactions 
Fig. 11 Southern Hemisphere composites for anomalous zonal mean zonal wind (shaded), meridional circulation vectors, and Coriolis torque $f[\bar{v}]$. The meridional vector is in units of $\mathrm{m} \mathrm{s}^{-1}$, the vertical in $\mathrm{mm} \mathrm{s}^{-1}$, and the contour interval for $f[\bar{v}]$ is $0.2 \mathrm{~m} \mathrm{~s}^{-1}$ day $^{-1}$. Negative contours of $f[\bar{v}]$ are associated with an anomalous easterly wind forcing

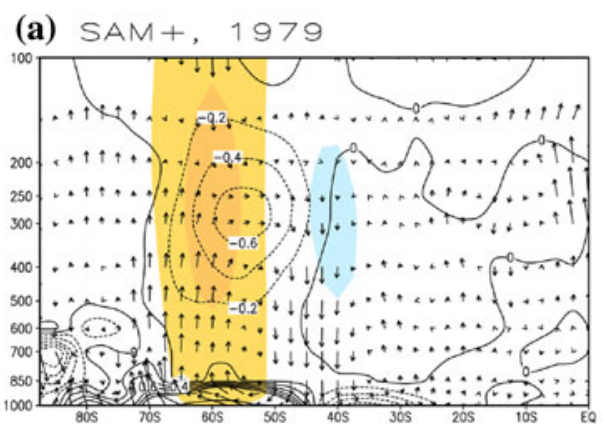

(c) $L N, 1979$

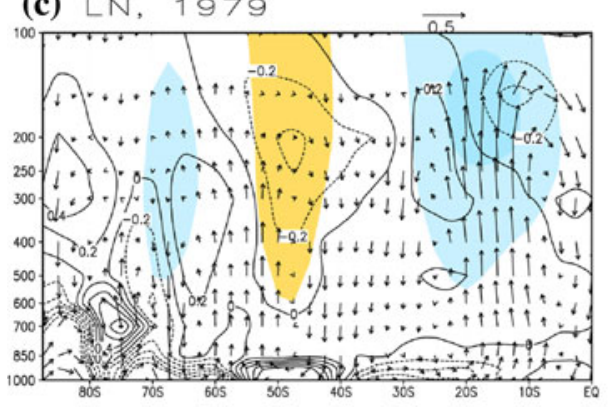

(e) $L N / S A M+, 1979$

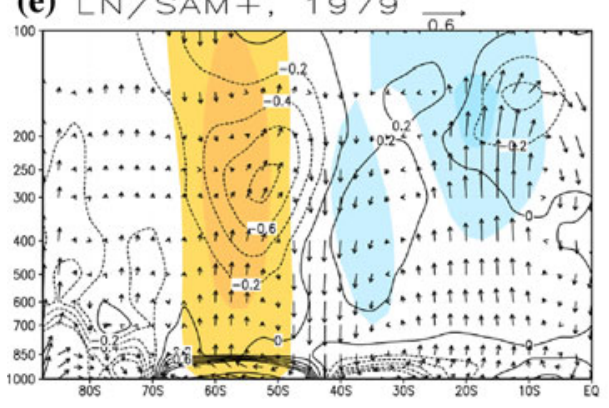

(g) $L N / S A M-, 1979$

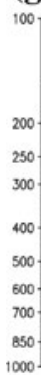

(b) SAM-, 1979

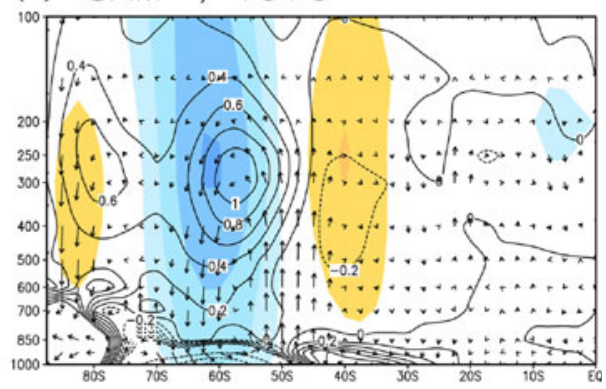

(d) $\mathrm{EN}, 1979$

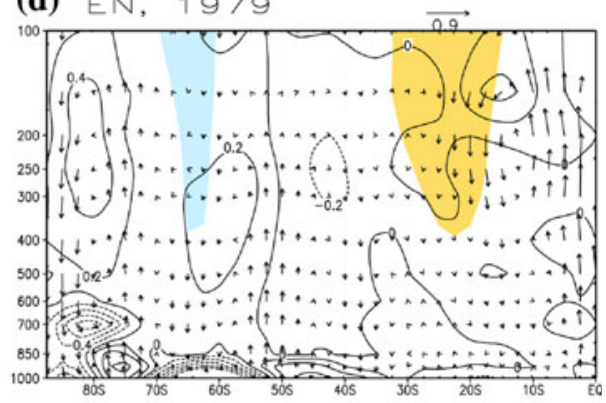

(f) $E N / S A M-, 1979$

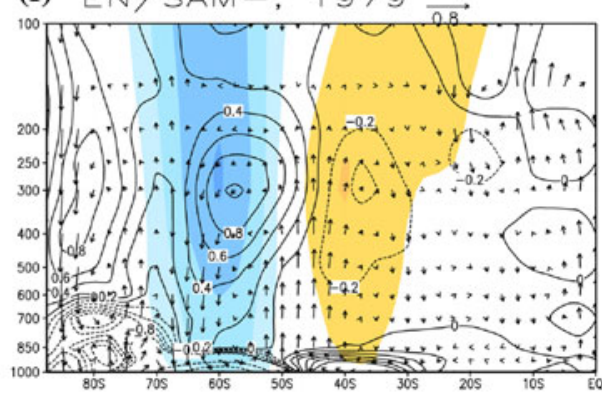

(h) $\mathrm{EN} / \mathrm{SAM}+, 1979$

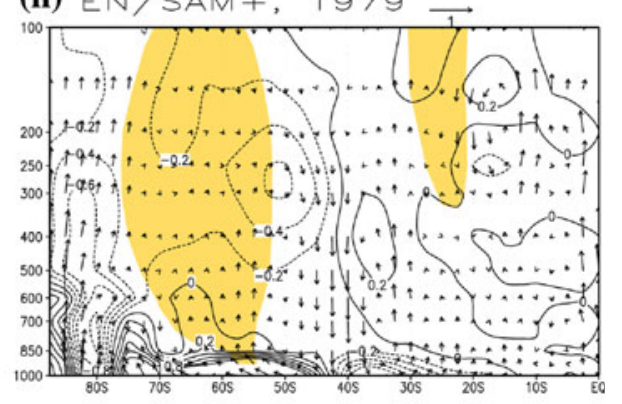

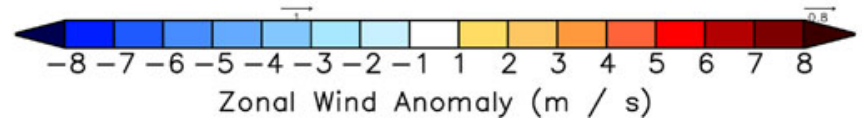

Zonal Wind Anomaly ( $m$ / s)

(Fig. 12) and their resulting circulation anomalies (Figs. 5, $6,7,8,9,10,11)$ have important implications for the magnitude of the South Pacific ENSO teleconnection. During in phase cases (Fig. 12e-f), the combination of both ENSO-related and SAM-related transient momentum fluxes act to reinforce the circulation anomalies present in the individual events. The influence of the positive SAM results in stronger poleward momentum fluxes in the midlatitudes for La Niña/SAM+ events than for La Niña events only. Further, there is a marked meridional broadening of the regions of anomalous transient poleward fluxes for the La Niña/SAM+ case, brought about by the fact that La Niña only events have an equatorward displacement of the region of maximum anomalous transient poleward momentum fluxes than for SAM+ only cases (compare Fig. 12a, c). For El Niño/SAM- cases (Fig. 12f), similarly 
Fig. 12 Southern Hemisphere composites for anomalous zonal mean zonal wind (shaded), anomalous meridional transient eddy momentum flux (thin contours; solid for positive; dashed for negative) and the anomalous transient momentum flux convergence, $-\frac{\partial\left[\overline{u^{\prime} v^{\prime}}\right]}{\partial y}$ (thick solid contours). The transient eddy momentum flux is contoured every $1 \mathrm{~m}^{2} \mathrm{~s}^{-2}$, and its convergence is contoured every $0.1 \mathrm{~m} \mathrm{~s}^{-1} \mathrm{day}^{-1}$. The momentum fluxes have been cosine weighted as in Seager et al. (2003), and the zero contour is omitted in both cases
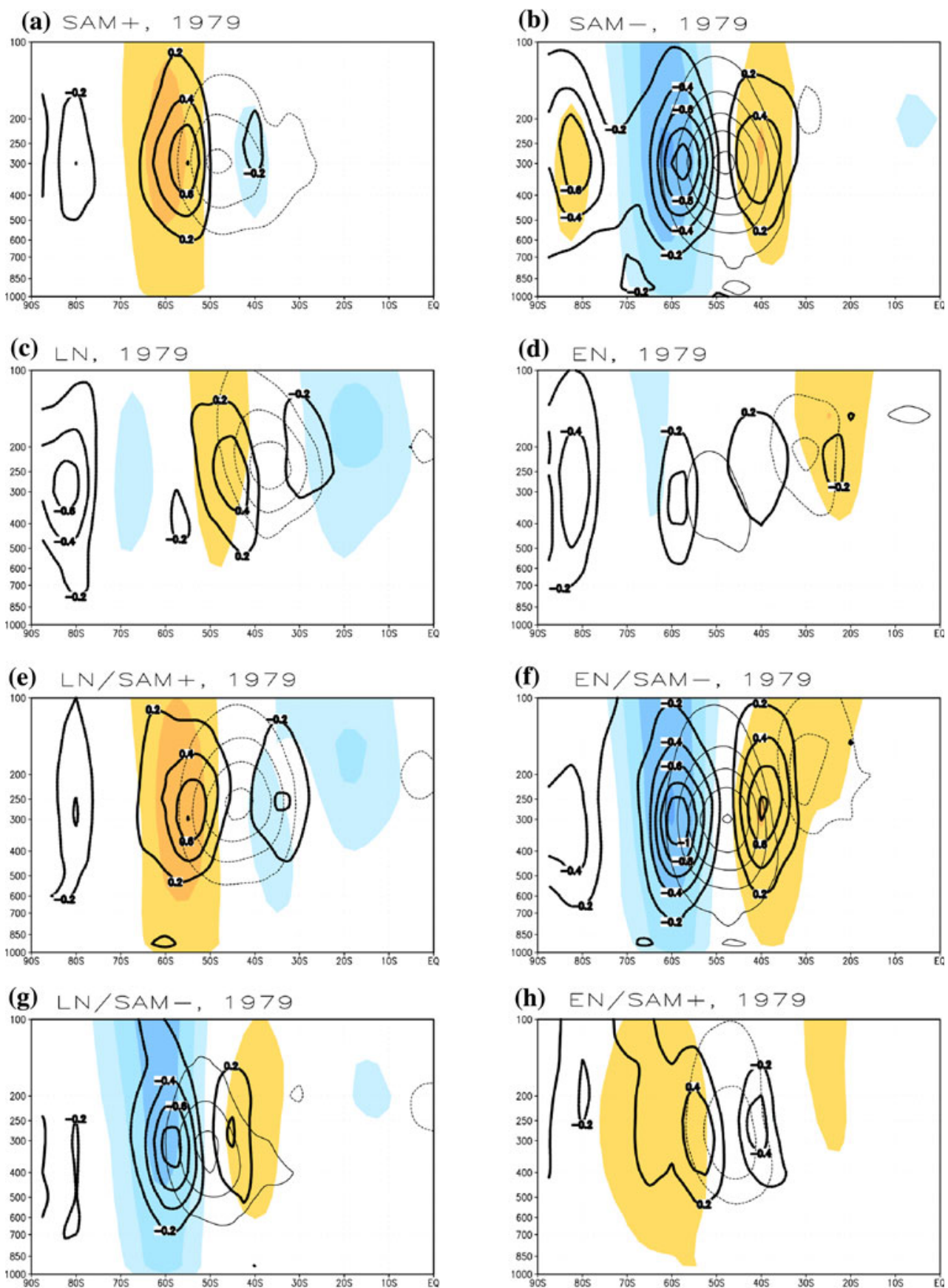

(h) $\mathrm{EN} / \mathrm{SAM}+, 1979$

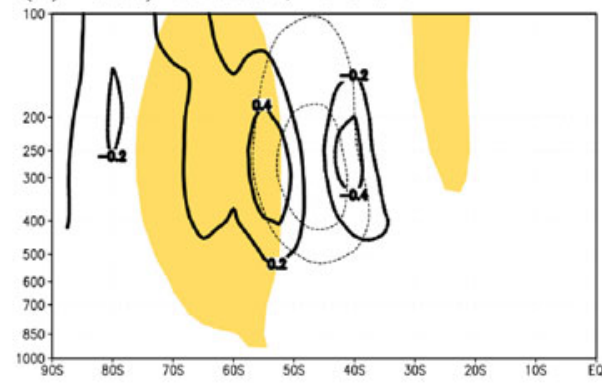

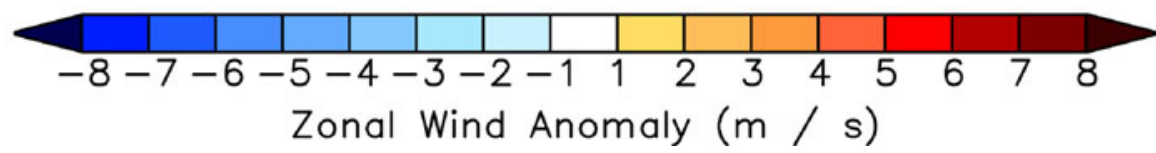

the influence of the negative SAM leads to much stronger anomalous equatorward transient momentum fluxes in the midlatitudes than seen in El Niño events alone (Fig. 12d).

In contrast, the influence of the opposing SAM events during the out of phase cases drastically reduces the anomalous poleward transient momentum fluxes associated with ENSO only events. For the La Niña/SAM - case, the expected anomalous poleward momentum fluxes during La Niña events in the Southern Hemisphere midlatitudes (Fig. 12c) are replaced by the anomalous equatorward momentum fluxes as seen in the SAM- only events (Fig. 12g, 12b). Similarly, the El Niño anomalous equatorward transient momentum fluxes in the Southern Hemisphere midlatitudes are not present when El Niño 
occurs with a SAM+; rather the midlatitudes are marked with anomalous poleward transient momentum fluxes which resemble the SAM+ only events (Fig. 12h, 12a). Since the transient momentum fluxes can also be thought of as fluxes of wave activity, the lack of the ENSO-related transient momentum fluxes in the midlatitudes further suggests that the atmospheric transport of the ENSO signal to the high southern latitudes via anomalous wave activity is dramatically reduced by the opposing forcing in the high southern latitudes associated with the strong SAM events.

Overall, the eddy interactions with the zonal wind anomalies are in agreement with Chen et al. (1996), who examined the variations in both the subtropical jet and the polar front jet in the South Pacific sector during the 1986-1989 ENSO cycle. They found that the variations in the polar front jet were strongly tied to eddy momentum flux convergence, particularly during the cold phase of ENSO, similar to the variations observed in the left panels of Fig. 12. Figure 12 also expands upon the study of L'Heureux and Thompson (2006) by considering separately the influence of positive and negative ENSO and SAM events and their combinations on the zonal-mean zonal wind. However, as noted earlier, the South Pacific ENSO teleconnection and its variations are most marked in the zonally asymmetric component of the circulation, especially in the Pacific sector, which is masked in the zonal mean perspective of Fig. 12.

To demonstrate that propagation of the ENSO signal to the high southern latitudes via anomalous wave activity (transient momentum fluxes) is most marked in the Pacific sector, and that its downstream teleconnection is dependent upon the phase of the SAM, we use the local $\mathbf{E}_{\mathbf{u}}$ vector formulation of Trenberth (1986, 1991). The meridional component of the $\mathbf{E}_{\mathbf{u}}$ vector is $-\overline{u^{\prime} v^{\prime}}$, the negative of the transient eddy momentum flux, while the zonal component is $\frac{1}{2}\left(\overline{v^{\prime 2}-u^{\prime 2}}\right)$. Based on the Trenberth (1991) representation, the $\mathbf{E}_{\mathbf{u}}$ vector points in the direction of the group velocity, and its divergence represents a westerly forcing, i.e., a strengthening of the local zonal flow. The $\mathbf{E}_{\mathbf{u}}$ vector composite anomalies at $300 \mathrm{hPa}$, where the transient eddies reach their maximum amplitude in Fig. 12, are plotted in Fig. 13. A corresponding composite plot of the $\mathbf{E}_{\mathbf{u}}$ divergence field based and the $300 \mathrm{hPa}$ zonal wind anomalies is given in Fig. 14. Although the $\mathbf{E}_{\mathbf{u}}$ divergence closely matches the $300 \mathrm{hPa}$ zonal wind anomalies, they are not expected to match one-to-one, since other factors such as the Coriolis torque acting on the residual meridional circulation and terms related to baroclinic forcing can also affect the local zonal wind anomalies (Trenberth 1986, 1991; Hoskins et al. 1983).

In the SAM+ only case, there is a strong divergence (convergence) of the $\mathbf{E}_{\mathbf{u}}$ vectors near $60^{\circ} \mathrm{S}\left(40^{\circ} \mathrm{S}\right)$, representing the strengthening (weakening) of the zonal flow there (Figs. 13a, 14a). In between these two latitudes are anomalous poleward transient momentum fluxes (or equatorward wave activity), also evident by the zonal mean representation in Fig. 12a. Notably, the $\mathbf{E}_{\mathbf{u}}$ vector magnitudes in the SAM+ case are weaker in the Pacific sector (Fig. 13a). Nearly opposite conditions are observed in SAM - only cases (Figs. 13b, 14b). During La Niña only events (Fig. 13c), the $\mathbf{E}_{\mathbf{u}}$ vector magnitudes are strongest in the Pacific sector, where they display a dominant meridional component. These $\mathbf{E}_{\mathbf{u}}$ vectors diverge strongly in the South Pacific, reflecting the zonal wind maximum at $45^{\circ} \mathrm{S}$, and converge near $25^{\circ} \mathrm{S}$ where they weaken the subtropical jet (Figs. 13c, 14c). Although weaker, the $\mathbf{E}_{\mathbf{u}}$ configurations and their influence on the zonal flow are nearly opposite in El Niño only cases, again most marked in the Pacific sector (Figs. 13d, 14d). A comparison of Figs. 13c$\mathrm{d}$ and $14 \mathrm{c}-\mathrm{d}$ with Figs. 12c-d therefore suggests the eddy forcing of the zonal wind anomalies is most marked in the Pacific sector, and does not span equally across all longitudes (i.e., Chen et al. 1996).

From Fig. 13a and c, it is again evident that the combination of $\mathrm{La} \mathrm{Niña/SAM+} \mathrm{is} \mathrm{a} \mathrm{situation} \mathrm{where} \mathrm{the}$ anomalous transient eddy momentum fluxes work together at most longitudes to enhance the mean flow and the resulting circulation (in terms of pressure/height anomalies). Most marked is the increased magnitude of the $\mathbf{E}_{\mathbf{u}}$ vectors in the Pacific sector in Fig. 13e as compared to $\mathrm{La}$ Niña only or SAM+ only events. The similar $\mathbf{E}_{\mathbf{u}}$ vector patterns imply the anomalous transient eddies from both $\mathrm{La}$ Niña and SAM+ reinforce, not oppose, one another. In turn, the positive interaction of the eddy fluxes allows for the La Niña response to be observed in the high latitudes during times of even very strong SAM+ events. A recent study by Gong et al. (2010) demonstrated that the anomalous flux of equatorward wave activity as seen in Fig. 13e alludes to the occurrence of strong anticyclonic wave breaking. The anomalous eddies associated with the changes in the region of anticyclonic wave breaking in turn drive zonal wind anomalies, which dynamically maintain the low pressure anomaly in the South Pacific (Figs. 5c, e, $6 c$, e). Similarly, the transient eddies similarly reinforce each other in the El Niño/SAM- cases, again evidenced particularly by the stronger $\mathbf{E}_{\mathbf{u}}$ vector magnitudes in the Pacific sector (Figs. 13f, 14f). As with La Niña, the preservation of anomalous poleward wave activity alters the region of anomalous cyclonic wave breaking required induce the zonal wind anomalies in Fig. 14f (Gong et al. 2010). These zonal wind anomalies in turn dynamically act to maintain a high pressure anomaly expected during El Niño in the South Pacific, even during strong SAMevents (Figs. 5d, f, 6d, f). 
(a) $\mathrm{SAM}+, 1979$

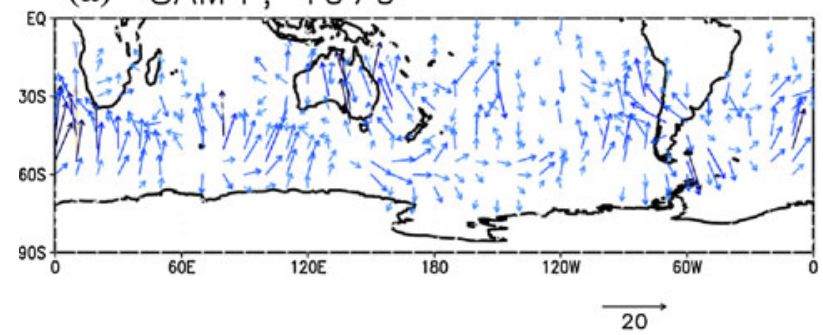

(c) LN, 1979

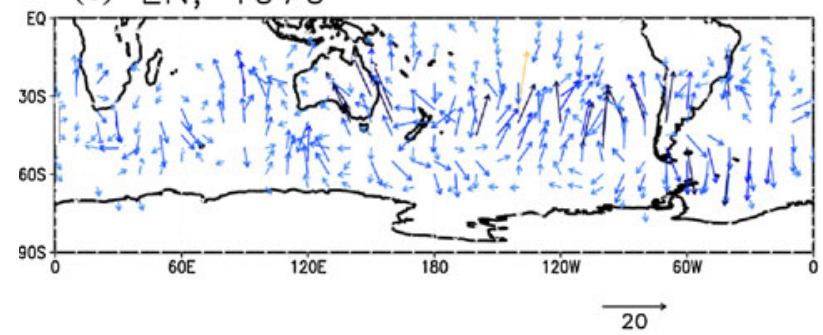

(e) $\mathrm{LN} / \mathrm{SAM}+, 1979$

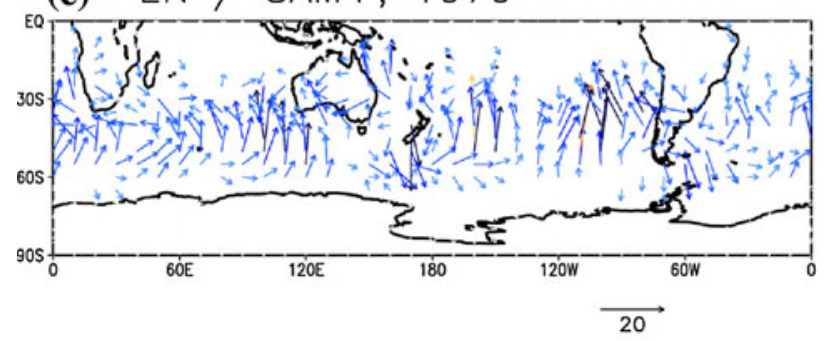

(g) LN / SAM-, 1979

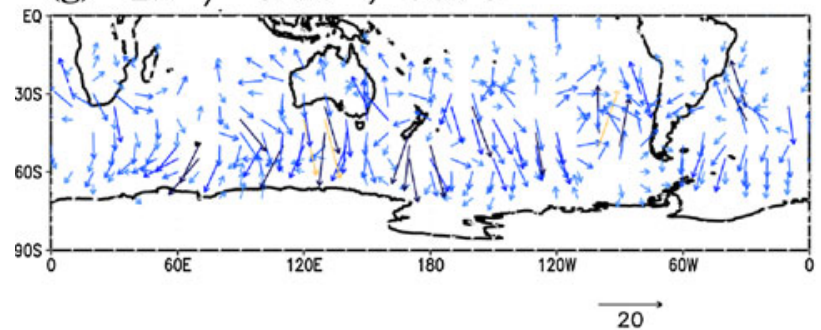

(b) $\mathrm{SAM}-, 1979$

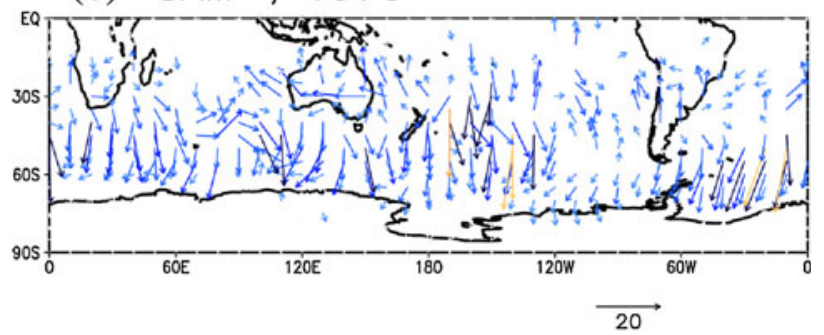

(d) $\mathrm{EN}, 1979$

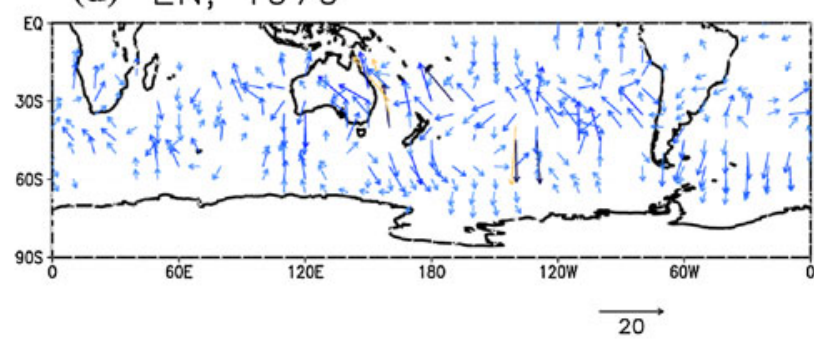

(f) $\mathrm{EN} / \mathrm{SAM}-, 1979$

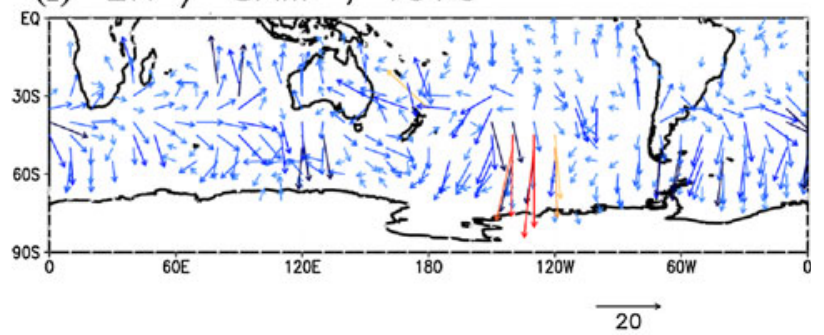

(h) $\mathrm{EN} / \mathrm{SAM}+, 1979$

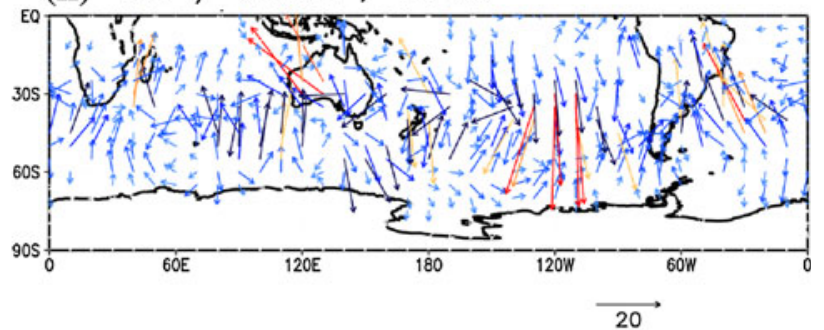

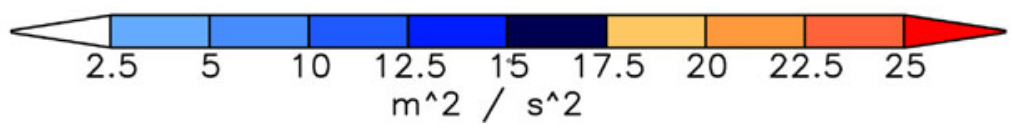

Fig. 13 Anomaly composites as in Fig. 5, but for the horizontal components of the $300 \mathrm{hPa} \mathbf{E}_{\mathbf{u}}$ vectors, 1979-2009. The vector magnitude is shaded

In marked contrast, Fig. $13 \mathrm{~g}$ demonstrates that the anomalous transient momentum fluxes from La Niña and SAM - oppose each other in the Pacific sector when both occur simultaneously. In the eastern Pacific, there is very little evidence of any transient eddy activity as the meridional component of the $\mathbf{E}_{\mathbf{u}}$ vectors is weak (Fig. 13g); the weak meridional component arises from cancellation of La Niña associated anomalous poleward transient momentum fluxes (inferred from Fig. 13c) with the anomalous equatorward transient momentum fluxes associated with SAM- (inferred from Fig. 13b). Meanwhile, the dominance of the equatorward momentum fluxes associated with SAM - overrides the poleward momentum fluxes associated La Niña only events, leading to a net flux of poleward wave activity (directed opposite of the transient eddy momentum flux) in the high southern latitudes across all other longitudes (Fig. 13g). The negative zonal wind anomalies resulting from the anomalous transient eddy momentum configurations (and associated regions of wave breaking and wave propagation) in turn drive the 
(a) $300 \mathrm{SAM}+, 1979$

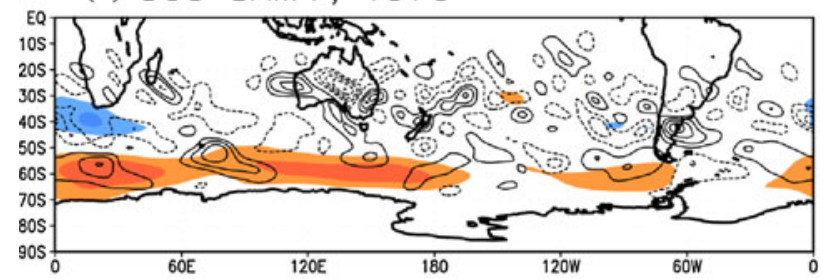

(c) 300 LN, 1979

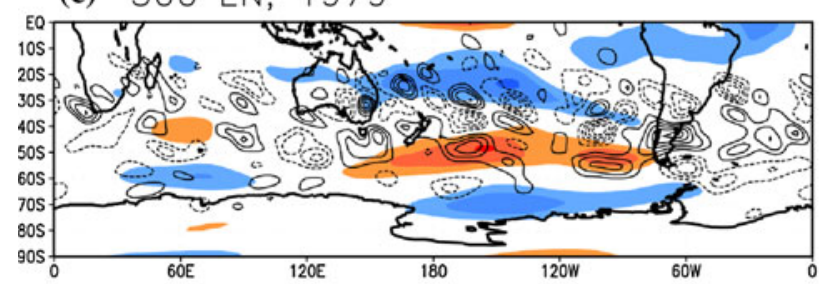

(e) $300 \mathrm{LN} / \mathrm{SAM}+, 1979$

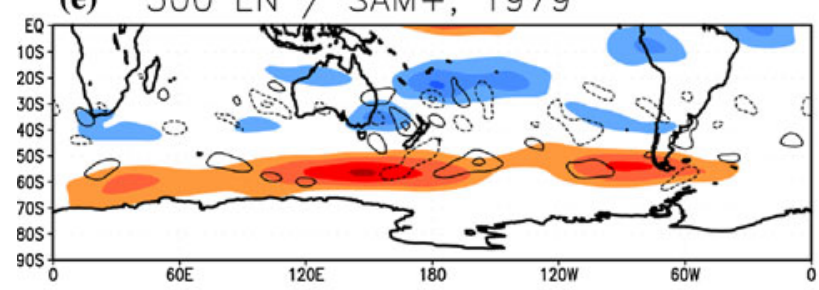

(g) $300 \mathrm{LN} / \mathrm{SAM}-, 1979$

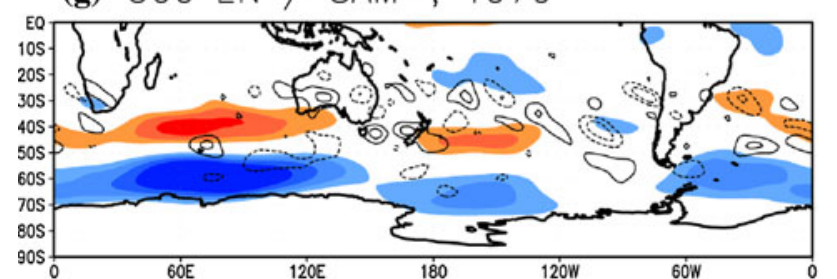

(b) $300 \mathrm{SAM}-, 1979$

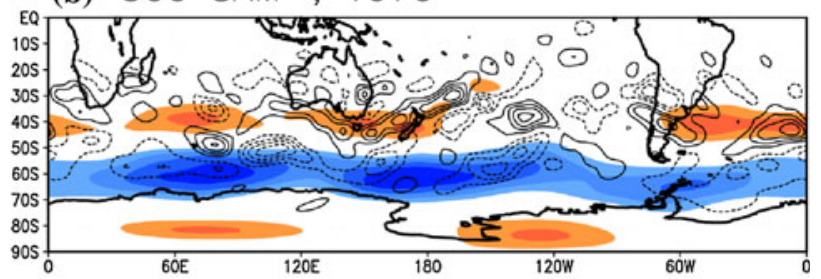

(d) $300 \mathrm{EN}, 1979$

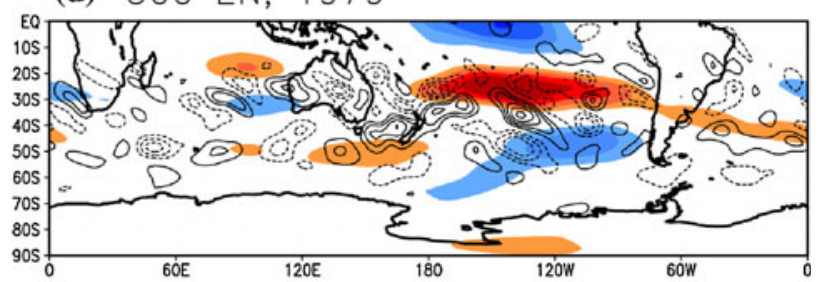

(f) $300 \mathrm{EN} \mathrm{/} \mathrm{SAM-,} 1979$

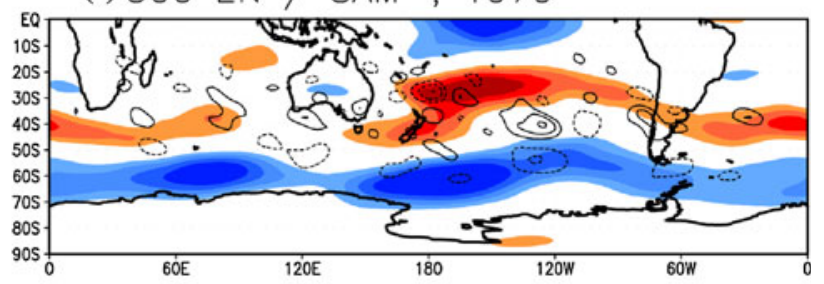

(h) $300 \mathrm{EN} / \mathrm{SAM}+, 1979$

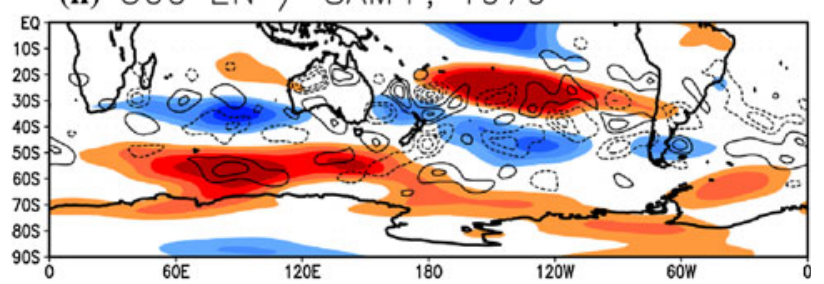

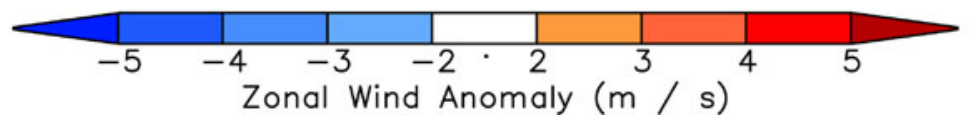

Fig. 14 Anomaly composites as in Fig. 5, but for the $300 \mathrm{hPa} \mathbf{E}_{\mathbf{u}}$ vector divergence (contoured at $0.01 \mathrm{~m} \mathrm{~s}^{-1}$ day $^{-1}$ ), and the zonal wind (shaded, $\mathrm{m} \mathrm{s}^{-1}$ ), 1979-2009

pressure anomalies observed in Figs. $5 \mathrm{~g}$ and $6 \mathrm{~g}$. As alluded to earlier, the South Pacific is left absent of any significant pressure anomalies associated with either ENSO or the SAM (Figs. 5g) as there is little net forcing from the transient eddies (Fig. 13g) here to drive significant zonal wind anomalies (Fig. 14g) needed maintain a persistent pressure anomaly. The result implies that the La Niña anomalous poleward transient momentum fluxes interfere with the anomalous equatorward transient momentum fluxes associated with the strong SAM- event in this region in such a way that the overall circulation anomalies in the
South Pacific are weak. Thus, not only is the magnitude of the ENSO teleconnection reduced during La Niña/SAMcases, but regional pressure anomalies associated with SAM- events (Figs. 5b, 6c) are also reduced in the South Pacific.

Figure $13 \mathrm{~h}$ provides insight as to why there is not as dramatic of a difference in terms of the pressure response in the South Pacific for in phase and out of phase El Niño/ SAM combinations post 1978 as there was for La Niña. In the El Niño only and the El Niño/SAM - case, there are equatorward transient momentum fluxes in the Pacific, 
particularly from $150^{\circ}-120^{\circ} \mathrm{W}$, evidenced by the $\mathbf{E}_{\mathbf{u}}$ patterns in Figs. 13d and f, respectively. In turn, the poleward flux of wave activity associated with these anomalous equatorward transient momentum fluxes alter the Southern Hemisphere pattern (Fig. 14d, f), resulting in the high pressure anomalies in the South Pacific (Figs. 5d, f, 6d, f). Somewhat surprisingly, these anomalous equatorward momentum fluxes are still present in the El Niño/SAM+ case (Fig. 13h), and are even stronger albeit confined to a smaller range of longitudes. The preservation of these transient momentum fluxes drives the zonal wind configurations in Fig. 14h, which maintain the positive pressure anomalies in the South Pacific seen in Figs. $5 \mathrm{~h}$ and $6 \mathrm{~h}$. However, the more regional nature of the anomalous equatorward transient momentum fluxes and the fact that they are surrounded by anomalous poleward transient momentum fluxes on both sides in Fig. 13h leads to a reduction in the area of statistical significance in the high pressure anomaly in the South Pacific.

\section{Discussion}

Relevant previous studies of ENSO and SAM have examined changes in eddy fluxes and the zonal mean flow (i.e., Seager et al. 2003; L'Heureux and Thompson 2006) and anomalous wave breaking (Gong et al. 2010). The dynamic analysis in Sect. 3c is consistent with these previous studies which considered SAM+ and La Niña events (or El Niño/SAM- events). Our results again find strong similarities between these events that in turn act to preserve the circulation anomalies observed during times when one mode acts in isolation. However, our study expands on these studies by showing opposite conditions: in the cases where ENSO and SAM events occur out of phase, it is the interference brought about by the underlying transient eddies associated with each event which act to reduce the regional circulation response. We have thus demonstrated, in light of the seasonal and decadal ENSO-SAM relationships discussed in Table 1 and Figs. 2, 3, 4 and other studies (Kwok and Comiso 2002; Fogt and Bromwich 2006; L'Heureux and Thompson 2006; Gregory and Noone 2008; Stammerjohn et al. 2008), the high latitude ENSO response is dependent on eddy-mean flow interactions in the South Pacific. In many cases, the forcing from the SAM and ENSO related eddies actually oppose each other in the South Pacific, resulting in weak circulation anomalies there.

Another interesting result from the analysis is in regard to the SAM structure. When examining circulation anomalies in SAM only events by removing the influence from strong ENSO events, we found that the SAM displays a more zonally symmetric structure across the high southern latitudes that previously depicted (Thompson and Wallace 2000; Marshall 2003). However, when strong ENSO events occur simultaneously with strong SAM events, the high southern latitudes have a more zonally asymmetric signature. In cases where SAM events are in phase with ENSO events, the zonal asymmetry is marked with strong anomalies in the region of the high latitude South Pacific. Because the asymmetry is lacking during times of weak ENSO activity, it is suggested that the zonal asymmetry in the South Pacific, seen in maps which show the correlation or regression of pressures/heights with the SAM in these previous studies, is primarily of tropical origin. This is further justified by the fact that when SAM events are out of phase with ENSO events, the interaction between the SAM-induced and ENSO-induced transient eddies also create marked asymmetries in the circulation in the South Pacific, especially based on the HadSLP2 dataset. The finding that the zonally asymmetric structure of the high latitude SAM is due to the remote influence of tropical SST variability is a new result, since previous studies have not investigated SAM events after removing the influence of ENSO events (Silvestri and Vera 2003; Fogt and Bromwich 2006; L'Heureux and Thompson 2006).

\section{Summary}

A first objective of this paper was to provide further insight on the ENSO-SAM relationships presented in previous studies (Silvestri and Vera 2003; Carvalho et al. 2005; Fogt and Bromwich 2006; L'Heureux and Thompson 2006). In examining the relationship, we note that both in phase and out of phase ENSO-SAM events show a seasonal preference: while the former tend to occur more often from November-February, the latter occur more often from May-October. A decadal relationship was also confirmed, and in particular a newly documented significant relationship in the 1970s associated with a large number of SAM only events that occurred more often than expected by chance and joint ENSO-SAM events that occurred less often than expected by chance.

The second objective of the paper was to determine if variations in the South Pacific ENSO teleconnection were significantly tied to the phase and magnitude of the SAM over the last 50 years. In agreement with Fogt and Bromwich (2006), and contrary to Sterl et al. (2007), the magnitude of this ENSO teleconnection is strongly related to the SAM magnitude and phase: the expected South Pacific ENSO response is only statistically $(p<0.05)$ different from climatology when an ENSO event occurs during a weak SAM event, or when it is in phase with the SAM (i.e., a La Niña occurs with a positive SAM and vice versa). It is notably absent when a La Niña occurs with the negative 
phase of the SAM (i.e., ENSO and SAM are out of phase) or no longer statistically significantly different from climatology when El Niño occurs with a positive SAM. The atmospheric circulation differences in the South Pacific between the in phase and out of phase SAM/ENSO combinations are significant $(p<0.05)$ and are more readily apparent during La Niña events.

A final objective was to provide a dynamic mechanism explaining the variations in the ENSO teleconnection strength through the various ENSO-SAM cases. An investigation of the transient eddy momentum fluxes and the $\mathbf{E}_{\mathbf{u}}$ vectors of Trenberth $(1986,1991)$ revealed that the teleconnection changes are linked to interactions between the ENSO induced and the SAM induced transient eddy momentum flux and associated wave propagation (and breaking, not shown) anomalies. When strong ENSO events occur in isolation (without any strong SAM forcing), the anomalous ENSO transient momentum fluxes, most marked in the Pacific sector, generate zonal wind anomalies that lead to the high latitude ENSO response. For in phase cases, the anomalous transient eddy momentum fluxes in the South Pacific reinforce each other in a way that acts to amplify the resulting circulation anomalies and maintain the ENSO teleconnection. The conditions vary somewhat for the out of phase cases. When a La Niña occurs with a negative SAM, the anomalous transient momentum fluxes oppose each other in the midlatitude Pacific Ocean, working against the expected ENSO signal from reaching the South Pacific. When an El Niño occurs with a SAM+, the El Niño transient momentum fluxes are still observed in the South Pacific, albeit more zonally confined. The presence of these transient momentum fluxes preserved the zonal wind anomalies associated with an El Niño event throughout much of the Pacific, and thus the high southern latitude El Niño teleconnection. However, because they occupy a smaller region of the Pacific due to the opposing anomalous transient momentum fluxes from the SAM+, the statistically significant area of the El Niño teleconnection is also reduced in El Niño/SAM+ events.

Given the recent dramatic climate changes along the Antarctic Peninsula and West Antarctica (Steig et al. 2009), understanding the regional atmospheric circulation variations linked to SAM and ENSO is paramount. However, much more work needs to be done. Modeling studies investigating the circulation response during various ENSO-SAM events are planned, in order to understand if models can adequately simulate the strong changes found in this study. Future work is also needed to investigate how the position of tropical convection during various ENSOSAM influences the high latitude ENSO teleconnection. This is especially important as Lachlan-Cope and Connolley (2006) demonstrate that the position of the convection within the tropical Pacific is also important for a significant downstream response during El Niño events.

Acknowledgments A portion of this work was conducted while RLF held a National Research Council Research Associateship Award at NOAA. All authors acknowledge support from NSF ATM grant \#0751291. RLF also acknowledges support from NSF OPP grant \#ANT-0944168. Two anonymous reviewers are thanked for their comments which helped to improve the manuscript and clarify our main points.

\section{References}

Allan R, Ansell T (2006) A new globally complete monthly historical gridded mean sea level pressure dataset (HadSLP2): 1850-2004. J Clim 19:5816-5842

Bromwich DH, Fogt RL (2004) Strong trends in the skill of the ERA40 and NCEP-NCAR reanalyses in the high and middle latitudes of the Southern Hemisphere, 1958-2001. J Clim 17:4603-4619

Bromwich DH, Monaghan AJ, Guo Z (2004) Modeling the ENSO modulation of Antarctic climate in the late 1990s with Polar MM5. J Clim 17:109-132

Bromwich DH, Fogt RL, Hodges KI, Walsh JE (2007) A tropospheric assessment of the ERA-40, NCEP, and JRA-25 global reanalyses in the polar regions. J Geophys Res 112. doi:10.1029/2006 JD007859

Carvalho LMV, Jones C, Ambrizzi T (2005) Opposite phases of the Antarctic Oscillation and relationships with intraseasonal to interannual activity in the Tropics during the austral summer. J Clim 18:702-718

Chen B, Smith SR, Bromwich DH (1996) Evolution of the tropospheric split jet over the South Pacific Ocean during the 1986-89 ENSO cycle. Mon Wea Rev 124:1711-1731

Comiso JC, Nishio F (2008) Trends in the sea ice cover using enhanced and compatible AMSR-E, SSM/I, and SMMR data. J Geophys Res 113. doi:10.1029/2007JC004257

Fogt RL, Bromwich DH (2006) Decadal variability of the ENSO teleconnection to the high latitude South Pacific governed by coupling with the Southern Annular Mode. J Clim 19:979-997

Gong T, Feldstein SB, Luo D (2010) The impact of ENSO on wave breaking and Southern Annular Mode events. J Atmos Sci (in press)

Gregory S, Noone D (2008) Variability in the teleconnection between the El Niño- Southern Oscillation and West Antarctic climate deduced from West Antarctic ice core isotope records. J Geophys Res 113. doi:10.1029/2007JD009107

Hines KM, Bromwich DH, Marshall GJ (2000) Artificial surface pressure trends in the NCEP-NCAR reanalysis over the Southern Ocean and Antarctica. J Clim 13:3940-3952

Hoskins BJ, James IN, White GH (1983) The shape, propagation, and mean-flow interaction of large-scale weather systems. J Atmos Sci 40:1595-1612

Jones PD, Lister DH (2007) Intercomparison of four different Southern Hemisphere sea level pressure datasets. Geophys Res Lett 34. doi:10.1029/2007GL029251

Kalnay R et al (1996) The NCEP-NCAR 40-year reanalysis project. Bull Am Meteorol Soc 77:437-471

Karoly DJ (1989) Southern Hemisphere circulation features associated with El Niño-Southern Oscillation events. J Clim 2:1239-1252

Kwok R, Comiso J (2002) Spatial patterns of variability in Antarctic surface temperature: Connections to the Southern Hemisphere 
Annular Mode and the Southern Oscillation. Geophys Res Lett 29. doi:10.1029/20002GL015415

L'Heureux ML, Thompson DWJ (2006) Observed relationships between the El-Niño/Southern Oscillation and the extratropical zonal-mean circulation. J Clim 19:276-287

Lachlan-Cope T, Connolley W (2006) Teleconnections between the tropical Pacific and the Amundsen-Bellingshausen Seas: role of the El Niño-Southern Oscillation. J Geophys Res 111. doi: 10.1029/2005JD006386

Lefebvre W, Goose H, Timmermann R, Fichefet T (2004) Influence of the Southern Annular Mode on the sea ice-ocean system. J Geophys Res 109, C09005. doi:10.1029/2004JC002403

Limpasuvan V, Hartmann DL (1999) Eddies and the annular modes of climate variability. Geophys Res Lett 26:3133-3136

Marshall GJ (2003) Trends in the Southern Annular Mode from observations and reanalyses. J Clim 16:4134-4143

Mo KC, Ghil M (1987) Statistics and dynamics of persistent anomalies. J Atmos Sci 44:877-901

Mo KC, Paegle JN (2001) The Pacific-South American modes and their downstream effects. Int J Climatol 21:1211-1229

Oort AH, Peixoto JP (1983) Global angular momentum and energy balance requirements from observations. Adv Geophys 25:355-490

Renwick JA, Revell MJ (1999) Blocking over the South Pacific and Rossby wave propagation. Mon Wea Rev 127:2233-2247

Schneider DP, Steig EJ (2008) Ice cores record significant 1940s Antarctic warmth related to tropical climate variability. Proc Natl Acad Sci 105:12154-12158

Seager R, Harnik N, Kushnir Y, Robinson W, Miller J (2003) Mechanisms of hemispherically symmetric variability. J Clim 16:2960-2978

Silvestri GE, Vera CS (2003) Antarctic Oscillation signal on precipitation anomalies over southeastern South America. Geophys Res Lett 30. doi:10.1029/2003GL018277

Smith TM, Reynolds RW, Peterson TC, Lawrimore J (2008) Improvements to NOAA's historical merged land-ocean surface temperature analysis (1880-2006). J Clim 21:2283-2296
Stammerjohn SE, Martinson DG, Smith RC, Yuan X, Rind D (2008) Trends in Antarctic annual sea ice retreat and advance and their relation to El Niño-Southern Oscillation and Southern Annular Mode variability. J Geophys Res 113. doi:10.1029/2007J C004269

Steig E, Schneider DP, Rutherford SD, Mann ME, Comiso JC, Shindell DT (2009) Warming of the Antarctic ice-sheet surface since the 1957 International Geophysical Year. Nature 457. doi: 10.1038/nature07669

Sterl A, van Oldenborgh GJ, Hazeleger W, Burgers G (2007) On the robustness of ENSO teleconnections. Clim Dyn 29:469-485

Thompson DWJ, Wallace JM (2000) Annular modes in the extratropical circulation. Part I: month-to-month variability. J Clim 13:1000-1016

Trenberth KE (1986) An assessment of the impact of transient eddies on the zonal mean flow during a blocking episode using localized Eliassen-Palm flux diagnostics. J Atmos Sci 43:2070-2087

Trenberth KE (1991) Storm tracks in the Southern Hemisphere. J Atmos Sci 48:2159-2178

Trenberth KE, Caron JM (2000) The Southern Oscillation revisited: sea level pressures, surface temperatures, and precipitation. J Clim 13:4358-4365

Turner J (2004) Review: The El Niño-Southern Oscillation and Antarctica. Int J Climatol 24:1-31

Ventura V, Paciorek CJ, Risbey JS (2004) Controlling the proportion of falsely rejected hypotheses when conducting multiple tests with climatological data. J Clim 17:4343-4356

Yuan X (2004) ENSO-related impacts on Antarctic sea ice: a synthesis of phenomenon and mechanisms. Antarct Sci 16: 415-425

Yuan X, Martinson DG (2000) Antarctic sea ice extent variability and its global connectivity. J Clim 13:1697-1717

Zwally HJ, Comiso JC, Parkinson CL, Cavalieri DJ, Gloersen P (2002) Variability of Antarctic sea ice 1979-1998. J Geophys Res 107. doi:10.1029/2000JC000733 